\title{
Estimating Treatment Heterogeneity of International Monetary Fund Programs on Child Poverty with Generalized Random Forest
}

\author{
Adel Daoud ${ }^{1, *}$ and Fredrik Johansson ${ }^{2}$
}

1. Center for Population and Development Studies, Harvard University, USA.

2. Clinical Machine Learning group, Massachusetts Institute of Technology, USA.

* corresponding author: adaoud@hsph.harvard.edu.

Version: 13 February, 2019

\begin{abstract}
A flourishing group of scholars of family sociology study how macroeconomic shockwaves propagate via households dynamics and landing a blow on children's living conditions; simultaneously, scholars of political economy unravel impacts of such shockwaves on population outcomes. Since these two strands of literature have evolved independently, little is know about the relative importance of societal and family features moderating this impact on children's material living conditions. In this article, we synthesize insights from these two strands by examining the effect of economic austerity following International Monetary Fund programs - a type of economic shock - on child poverty across a sample representative of about half the world's population of mainly the Global South. This article addresses the following fundamental sociological questions: to what extent do the pathways of economic austerity propagate through families' living conditions and societies' structural and political characteristics. To capture these multiple non-linear heterogeneous relationships between macro and micro traits, we deploy machine learning in the service of policy evaluation. First, our analysis identifies an adverse average treatment effect (ATE) following the implementation of IMF programs on children's probability of falling into poverty: 0.14, 95\% CI 0.03- 0.24. Second, our algorithms identify substantial impact heterogeneity distributed about this ATE. Macro constellation moderate about half of the impact variation on children, and families' capabilities moderate the other half of this variation. We named this finding the 50-50 impactmoderation rule of thumb. Our algorithm identified family wealth closely followed by governments' education spending as the critical moderating factors. IMF program affects children residing in the middle of the social stratification more than compared to their peers residing in both the top and bottom of this stratification; for those children residing in societies that have selected into IMF programs and have historically spent most on education, are at a higher risk of falling into poverty. These findings identify the value of combining family sociology and political economy perspectives. Scholars will likely cross-fertilize this research further by testing this 50-50 rule of thumb to other types of economic shocks.
\end{abstract}

Acknowledgments: Prof. Christopher Winship, Harvard University; Prof. Jason Beckfield, Harvard University; Prof. Lisa Berkman, Harvard University; Sebastian Kohl, Max Planck Institute for the Studies of Societies; Elias Nosrati, University of Oxford; Bernhard Reinsberg, University of Glasgow; Leslie Adams, Harvard University; Emilie Courtin, Harvard University; Angela Dixon, Harvard University ; Beth Truesdale, Harvard University. 


\section{Contents}

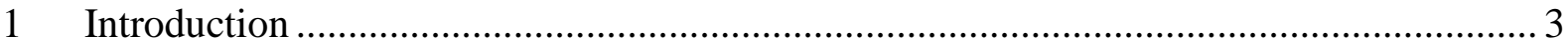

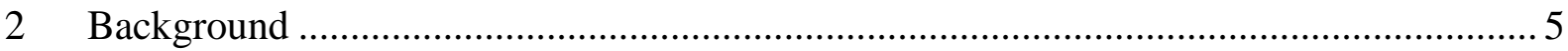

2.1 The International Monetary Fund (IMF) programs as a strategic research site ......... 5

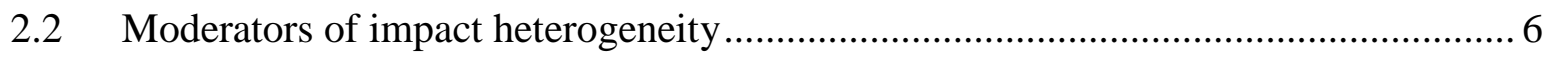

2.2.1 Micro moderators: Families' capabilities to protect their children ...................... 6

2.2.2 Macro moderators: the political economy of economic shocks and poverty ....... 8

2.2.3 Linking macro and micro: the quincunx metaphor ......................................... 10

3 Conceptual framework: identification of IMF treatment on child poverty ..................... 10

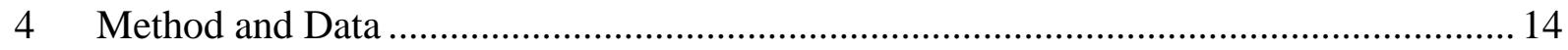

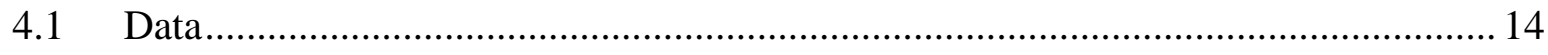

4.1.1 Micro: families and their children's living condition....................................... 14

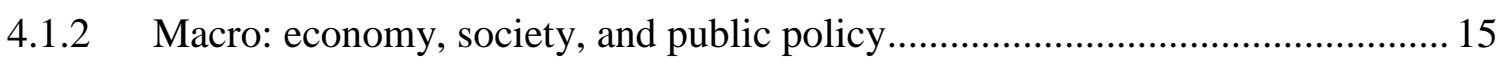

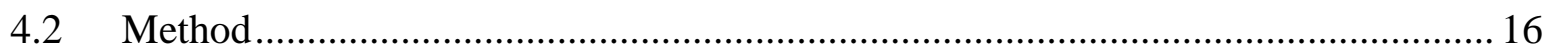

4.2.1 Machine learning in the service of policy evaluation....................................... 16

4.2.2 Generalized random forest .............................................................................. 17

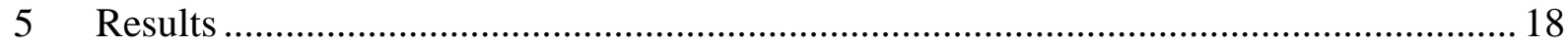

5.1 The average impact of IMF programs on child poverty ....................................... 18

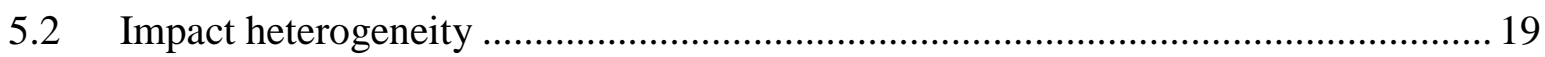

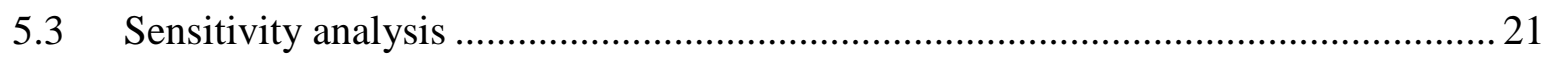

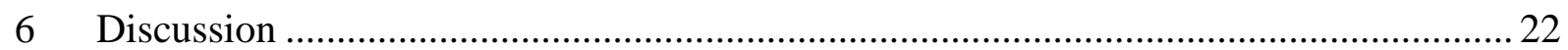

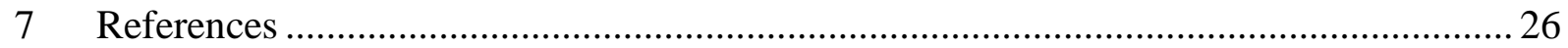

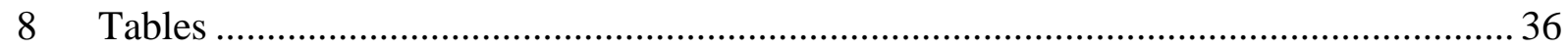

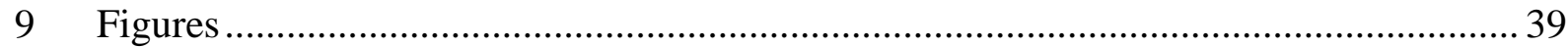

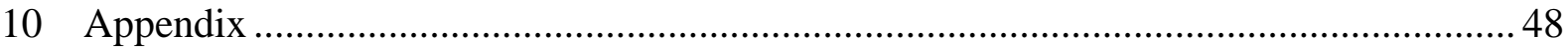

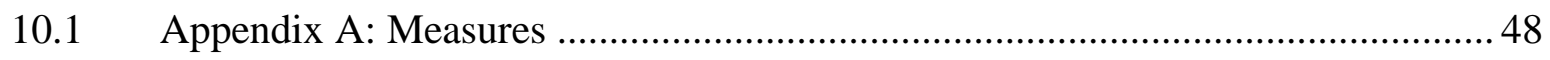

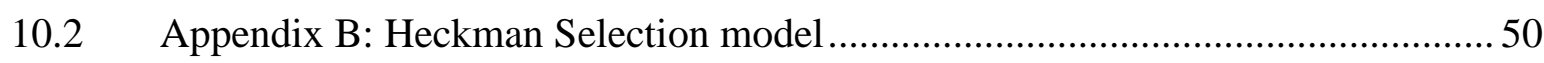




\section{Introduction}

Since the formation of their discipline, sociologists have been theorizing about the impact of economic change on people's living conditions (Smelser and Swedberg 2005). Scholars have upheld this intellectual tradition by producing a variety of influential studies on the relationship between poverty and, for example, the impact of incarceration (Western 2002), deindustrialization, urban segregation (Desmond 2012), neoliberalism (Wacquant 2009), European and American public policy (Amenta and Carruthers 1988; Brady 2005; Desmond and Western 2018; Dobbin 1993). Although research on the impact of economic crises on inequality is growing (Grusky, Ku, and Szelényi 2008; Jenkins et al. 2012), the link between economic crises and poverty is less well understood through a sociological lens (Redbird and Grusky 2016). Sociologists have analyzed the erosion of trust of the 2008 Great recession and the social construction of the Great Depression (Dobbin 1993; Swedberg 2013). Economists and political scientists have found that economic turmoil affect proximate outcomes such as unemployment, inflation, and fiscal cuts (Bermeo and Pontusson 2012; Claessens et al. 2010; Laeven and Valencia 2013; Pontusson and Raess 2012; Ravallion 2015; Reinhart and Rogoff 2008), but also distal outcomes such as infant mortality (Baird, Friedman, and Schady 2010). Furthering this state-of-the-art from a sociological perspective is likely to yield insights about the relative importance of macro and micro conditions affecting poverty amid crises.

Varieties of social science theories economic crisis and poverty have evolved relatively independently. Of the micro studies, Elder's pioneering study, (1974) Children of the Great Depression, have inspired a stream of social psychological and social demographic analyses of family dynamics. This body of research assumes that economic shocks operate mainly through individual-level pathways (Garfinkel, McLanahan, and Wimer 2016; McLanahan and Percheski 2008). When the breadwinners of the household lose their jobs, it leads to a cascading effect of worsened material standards. Financial strain increases family stress and that significantly increases the risk of deteriorated child well-being and poverty. Scholars of macro studies have sought inspiration instead in institutional and policy determinates of crises and poverty (Babb 2005; Hall and Lamont 2009). These sociologists have devoted energy to analyze the effects of economic crises and austerity policies emanating from the International Monetary Fund (Babb 2005; Halliday and Carruthers 2009; Kentikelenis, Stubbs, and King 2016). These studies have, for example, analyzed the impact of IMF on public policy (Daoud and Reinsberg 2018; Shandra, Shandra, and London 2012), institutional change in Eastern European after the dissolvent of the Soviet Union (Hamm, King, and Stuckler 2012). Macro perspectives tend to focus on child outcome insofar that this measures is a "... sensitive indication of social development” (Conley and Springer 2001:770). Nonetheless, scholars of micro and macro studies have had little exchange about the effect of crises on families.

The relatively independent evolution of micro and macro bodies of research have influenced the state-of-the-art of poverty in at least two ways. First, a lack of engagement between these bodies of research has restricted our social scientific knowledge of the topic (Brady forthcoming). Both bodies of research make significant contributions to our understanding of how crisis affect vulnerable populations such as children, yet they tend to accentuate one of two analytical units. Accordingly, a key puzzle of the state-of-the-art refers to the relative importance of macro and micro. What portion of the impact of economic turmoil on families and their children's living conditions consist of differences between societies versus differences between households (Burgard and Kalousova 2015; Garfinkel et al. 2016; McLanahan and Percheski 2008). This is a core sociological issue of structure versus agency (Durkheim 1979; Weber 1949). Due to the variability in families' resources and behavior capacities following their position in the social strata, economic shocks will likely produce a large amount of impact 
heterogeneity. As Goldthorpe, and others have emphasized, the discipline requires a framework "through which variability and heterogeneity can be accommodated and in various ways exploited.” (Goldthorpe 2015:31). Such a systematic approach is currently lacking.

Second, the intellectual insulation between macro and micro perspectives of the study of crisis and poverty has created a geographical fault line between studies of Global North and South (Brady and Burton 2016; Viterna and Robertson 2015). While macro oriented political economy studies tend to focus on the global system, micro oriented family sociology and welfare studies have a Global-North focus (Esping-Andersen 1990; Garfinkel et al. 2016; Korpi and Palme 1998; McLanahan 2009; McLanahan and Percheski 2008). Extending this topic to non-Western societies is a key mission of social demographic and social stratification researchers (Beckfield 2018; Brady forthcoming). Hence, acquiring deeper knowledge about how families residing in the Global South cope with economic shocks would enhance sociological theory on whether these families respond differently to such dramatic events (Ayuso-Mateos, Barros, and Gusmao 2013; Cherlin 2012).

The overarching research goal of this article is to advance the state-of-the-art by fulfilling two aims. The first aim is to identify the effect of economic shocks of International Monetary Fund austerity programs on child poverty in the Global South. Foreshadowing the scholarly debates outlined, we selected the IMF as exposure of economic crisis and child poverty as an outcome since these two features have been the focus of considerable debate in political economy and family sociology, respectively. The family stress model has almost exclusively focused on children's risk of poverty thought out their life course (Garfinkel et al. 2016). Welfare and political economy studies have devoted considerable energy to investigating the effects of IMF austerity programs (Babb 2005). This article focus on the Global South as a complement to the Global North focused family sociology literature (Viterna and Robertson 2015). To this end, we analyze large data combining societal, family, and child-level samples of about 2 million children residing in 67 of these societies. These data are representative of about half the world's population.

The second aim is to evaluate the relative importance of societal characteristics and family features in moderating IMF program's impact (treatment effect) heterogeneity on children. We analyze to what extent the impact of an economic shock on child poverty moves the entire distribution of a population versus merely certain individuals or social strata within a population (Xie 2013). By identifying how this type of economic turmoil affect children, we will gain a deeper understanding of how much their lives are governed by structural versus family conditions (Goldthorpe 2015). If the entire population distribution of children's outcome is shifted due to economic turmoil, then this is evidence of macro conditions eclipsing families' leeway to deal with economic stress. The opposite holds if we find instead that this distribution of outcomes shifts due to differences between families, for example, due to their wealth or parents' education (Beckfield 2018; Gkiouleka et al. 2018).

The second aim requires a methodology possessing the capability to identify heterogeneous effects of IMF economic shock inductively. Such a methodological tool has to satisfy, what Abbott has called, "transcending general linear reality" (Abbott 1988). A burgeoning methodological literature proposes that machine learning in the service of policy evaluation is well equipped to handle this challenge (Athey and Imbens 2017; Belloni et al. 2017; Hill 2011; Johansson, Shalit, and Sontag 2016; Kraamwinkel et al. 2019; Mullainathan and Spiess 2017). We outline in the method section in which way our analysis will rely on this technique. 
Consequently, a methodological contribution of this paper is that it exemplifies how sociologists can benefit from these learning algorithms to identify population heterogeneities.

Our main findings corroborate the intuition of those who seek to bridge macro and micro poverty studies. Firstly, the economic shockwaves following IMF interventions produce adverse risks for children. Children will face an increased probability of poverty by 14 percent, on average. Secondly, the variation in impact heterogeneity partitions neatly into a simple 5050 rule. Macro differences between-societies_-e.g., policies, culture, institutions, demography, economy-account for about half of the variation of IMF effects on children's risk of poverty. Micro differences between- and within-families capture the other half of the impact variatione.g., parents' choice of residence, their resources, choices, and behavior. This 50-50 heterogeneity rule reinforces the proposition that the two bodies of political economy and family sociology will benefit from each other's frameworks.

The next section outlines the state-of-the-art on the macro and micro factors of society-wide economic shocks on poverty. At the end of this section, we define our conceptual framework and its identification strategy. This framework includes (1) how we isolate the effect of IMF programs on child poverty, and (2) how we determine to what extent the impact heterogeneity is driven by the economy, politics, and families' capabilities. The method section highlights what advantages our analysis gains by using a machine learning approach to estimating crisis impact compared to other estimations techniques. This section will also explicate the limitation of this approach, and what assumptions we have to rely on. This section will show the data we have assembled. The results section outlines our findings laying out a series of the distributions faceted by societal versus family characteristics. We close this paper by discussing what we have learned from these findings and suggest ways forward for a synthesized theoretical framework of political economy and family sociology.

\section{Background}

\subsection{The International Monetary Fund (IMF) programs as a strategic research site}

The case of IMF programs offers a "strategic research site" (Merton 1987); it provides a set of advantages. An advantage of using IMF programs as a proxy for economic shocks is that these programs provide validated cases of economic crisis (Ragin 2008). The incentive for a government experiencing an economic downturn to enroll in often draconian austerity programs usually is only justified when its economy is indeed in a downward spiral (Vreeland 2007). Likewise, as IMF's resources are scarce, it tends to focus efforts on those types of societies' that experience large macroeconomic imbalances. Many of the previous studies of crises and poverty use unemployment or economic growth rates as proxies of economic crisis (Claessens et al. 2010; Grusky, Western, and Wimer 2011; Kindleberger and Aliber 2011; Laeven and Valencia 2013). However, one disadvantage of using such rates is that it is unclear what thresholds classify a crisis. Many societies, especially in the Global South, usually have a higher level and variability of unemployment rates compared to the Global North (Ravallion 2015). Thus, it is unclear if the analysis is comparing apples to apples when using unemployment or growth rates as a proxy for economic crises.

Nonetheless, there is one major challenge of using IMF as a proxy for crises: risk of selection bias. Some governments have larger political motivation to self-select into IMF programs than other governments (Stubbs et al. 2018). Governments self-select for a variety of reasons. For 
example, they might have a weak state-capacity insufficient to collect taxes; they can be market liberal seeking to use the IMF as a scapegoat when implementing unpopular reforms (Vreeland 2007). We outline how we handle self-selection bias-our identification strategy-in our conceptual framework and method sections.

Another reason to analyze IMF programs is that they provide a quasi-experimental design where sudden shifts in public policies occur. While economists have mainly focused on the macroeconomic effects of IMF policies (Butkiewicz and Yanikkaya 2005; Vreeland 2003), sociologists and other social scientist have researched the implications for vulnerable populations (Babb 2005; Cline 2004; Daoud et al. 2017). Thirty years ago, the publication of a landmark UNICEF report first drew attention to the adverse effects of the policies of these programs on the poor (Cornia, Jolly, and Stewart 1987). IMF policies are known to be promarket, and thus, they require often that governments reduce their public and social spending (Babb and Carruthers 2008; Williamson 1990). This reduction tends to affect the poor more than other social strata. Along this causal pathway, a stream of research finds a short-term adverse effects of these programs on poverty and health (Babb 2005; Basu et al. 2013; Daoud et al. 2017; Daoud and Reinsberg 2018; Shandra et al. 2004; Shandra, Shandra, and London 2011; Shandra et al. 2012; Stubbs and Kentikelenis 2018; Stuckler, King, and Basu 2008; Thomson, Kentikelenis, and Stubbs 2017). From a welfare state and public policy perspective, these adverse effects mediated by reduced social spending are not surprising. However, since most of these studies do not use microdata, less is known about impact heterogeneity following IMF programs (Bal Gündüz 2016). By impact heterogeneity, we mean the variation in how families and their children respond differently to the same policy (treatment) changes due to IMF programs (Grimmer, Messing, and Westwood 2017).

\subsection{Moderators of impact heterogeneity}

Although scholars of poverty research have produced a torrent of insightful work (Alkire 2015; Banerjee and Duflo 2012; Bradshaw 2000; Brady and Bostic 2015; Desmond and Western 2018; Ravallion 2015; Sen 1999; Townsend 1987; Wacquant 2009), the field lacks a clear sociological theory of causation. This theory ought to, among other things, explain how economic downturns affect poverty. David Brady has recently proposed a framework dealing with this lack (Brady forthcoming). His framework categorizes the type of mechanisms affecting poverty in three categories. The first category contains micro, or behavioral, oriented theories of poverty causes. These micro theories focus on individuals' actions, choices, and resources (Bertrand, Mullainathan, and Shafir 2004; Conger et al. 1992; Gibson-Davis, Edin, and McLanahan 2005; Mitchell et al. 2015). The second category holds structural explanations of poverty. These explanations refer to the macro-level demographic and economic conditions moderating economic crises (Babb 2005; Brady and Bostic 2015; Tomaskovic-Devey 1991). The third category comprises a second type of macro explanations of poverty: polity, policy, and institutions. These explanations hold that the impact of crises has to be understood as a function of the aggravating or cushioning policies and governance (Brady, Blome, and Kleider 2016). In the following sections, we adapt Brady's framework to our economic-crises-andchild-poverty context.

\subsubsection{Micro moderators: Families' capabilities to protect their children}

Parents' capabilities influence their children's development and well-being; macroeconomic shocks multiply this influence. The Elder-Conger model, generally known as the family stress model, describes how the onset of an economic downturn pressures household dynamics (Boss, Bryant, and Mancini 2016; Conger, Conger, and Martin 2010; Conger and Donnellan 2007). The focus of this model is to analyze the family conditions-resources, behavior, and choicesthat govern the relationship between parents and their children. These conditions create 
pathways through which the effects of a macroeconomic shock propel ultimately affecting children's material and emotion outcomes directly, but also throughout their life course. Among the most important pathways are parents' employment, income, and children's access to other resources through public resources. Children's entitlements to quality healthcare and schooling are especially important in developing societies since many social programs are tied to these two sectors (Banerjee et al. 2015). Changes in these conditions, for example, when parents unexpectedly lose their jobs, aggravates family dynamics that can trigger drastic measures (Conger et al. 1992). Emotionally, adults can become abusive of their children (Wood et al. 2012) or neglect them (Straus, Gelles, and Steinmetz 1980). Materially, responding to a reduction in family income, parents cut expenses for food (Conklin et al. 2018; Nandy, Daoud, and Gordon 2016; Ponce et al. 2017), clothing, medical care, and education (Puaca and Daoud 2011; Schneider, Hastings, and LaBriola 2018).

Material and emotional childhood disadvantages can lead to personal and social issues in middle and later life, compared to those families that did not experience economic hardship (Ferraro, Schafer, and Wilkinson 2016; McLoyd, Jocson, and Williams 2017). For example, boys are more likely to act out than girls, putting them at higher risk of deviant behavior as adults (Schneider, Waldfogel, and Brooks-Gunn 2015). Disadvantaged children tend to have weaker mental health (McLeod and Shanahan 1993), more criminal offenses (Laub and Sampson 2009), lower educational attainments and employability (Daoud and Puaca 2011; McLoyd 1998), compared to their peers that have been spared from economic turmoil in their childhood. They tend to also live in more segregated neighborhoods, further restricting their life-chances (Owens 2016). All these factors increase their risk of poverty during childhood and adulthood. Nonetheless, what scholars know less about is how these types of childhood disadvantages affect children's risk of poverty later in life, from a global perspective.

Elder and Conger seminal work have inspired a stream of research on the stressors of American and European families. Elder (1998) analyzed the impact of the great recession, while Conger led a study on the impact of the Iowa farm crisis of 1980 on adolescent boys (Conger et al. 1992; cf. Leininger and Kalil 2014). These studies have spurred a number of country-specific analyses: for example, Kinnunen et al. (2004) analyzed the economic stress of Finnish families; Aytaç et al. (2009) tests the family stress model, focusing on marital problems, in Turkish households; Hraba et al. (2000) identify the effect of the Czech economic transformation on families' material outcomes, and; Garfinkel et al. (2016) provides an in-depth analysis of how American children's well-being has deteriorated following the 2008 financial crisis. Yet, except some studies of the Asian economic crises (Kwon et al. 2003; Ramesh 2009) and aggregated studies (Shandra et al. 2012), little is known about the effects of economic crises on families and their children's material living conditions in a global comparative perspective. Focusing on the potential economic shockwaves arising due to IMF interventions is a particularly important research task. If these shockwaves ever materialize - in other words, if IMF programs fizzlethey arise due to mainly man-made intentionally ascribed economic policies. Other types of economic crises tend to arise due to the unintended consequences of human actions (Kindleberger and Aliber 2011). To what extent IMF shocks increase children's probability of poverty, is an open question. Kwak et al. (1999) identify an adverse effect, but the sample captures only South Korean families. Daoud et al. (2017) finds a similar adverse effect in a global sample, but focus on children's health. The relationship between IMF and poverty is unique. IMF programs can be independent of child poverty if austerity measures affect policy areas not relevant to children-health and education systems. However, these programs can still increase the risk of poverty if they target areas that increase job precariousness for vulnerable families (Babb 2005). 
Unearthing how crises affect poverty globally would enable sociologists to portrait a broader image of how families deal with economic downturns. This will eventually enable them to compare these children with their European and American peers, and thus, and theorize to what extent the mechanisms are comparable across this broader landscape of societies (Beckfield 2018; Sosnaud and Beckfield 2017).

The family stress model, motivated by a social psychological foundation, ascribes most of the causal action to intra-household dynamics (Conger et al. 1992). Children's outcomes are a function of their parents' actions, and these actions are in turn a function of the parent's command over family resources. This model captures an essential part of how economic shocks are likely mediated from societal events to individual outcomes in a chain of causal links. However, this focus on the family members as atomic units potentially misses the broader institutional conditions moderating impact heterogeneity of children's material outcomes due to macroeconomic shockwaves (Brady forthcoming).

\subsubsection{Macro moderators: the political economy of economic shocks and poverty}

The impact of economic crises propagate through two macro pathways: structural and political(Brady forthcoming).

Structural pathways: these pathways of poverty refer to the macro-level demographic and economic conditions moderating economic crises (Benatar, Gill, and Bakker 2011; Tomaskovic-Devey 1991). These structural explanations do not preclude individuals' agency, but they tend to underscore the macroeconomic and demographic conditions explaining such actions as fundamental causes. These economic conditions could refer to crises causing breaks in economic development, sudden trade liberalization affecting domestic industries, and the emergence of precarious labor market due to intensifying economic globalization. For example, the 2008 financial crisis hampered not only activities at Wall Street but also rapidly spread throughout the global financial system. This crisis also had a significant impact on developing societies that were export-dependent. Due to falling demand from industrialized countries, Zambian, for example, lost 27 percent of its jobs in the mining sector in 2008-9 (Green 2009); Cambodia construction sector lost about 5 percent of its jobs during the same period (ODI 2009, p. 1). These economic shocks tend to increase unemployment more than any other type of societal shock (Kindleberger and Aliber 2011). The IMF offers its support to the governments of these nations when banking or currency crises lead to sovereign debt crises. However, little is known about how families with different capabilities respond to these particular IMF related economic stressor. To what extent do these stressors affect parents' capacity to care for their children's material living standards, is insufficiently researched.

The Washington Consensus influences the policy content of IMF programs (Kentikelenis et al. 2016). To promote international trade, many of IMF's policies will reduce hinders to trade in the form of lowering tariffs, eliminating subsidies, and removing obscuring regulation to open up societies. This makes it easier for foreign companies to enter these markets. More businesses imply more job opportunities and higher economic growth. That is the vision of the Washington Consensus. To promote domestic markets, the IMF will aim to reduce the state's interventions in the economy. This can comprise the privatization of health care and education (Rowden 2011; Stubbs et al. 2017). Researchers have devoted considerable effort to evaluate the impact of IMF on populations, yet mainly using aggregated country-level data. These aggregated data masks the precision of capturing the heterogeneous impact of these structural economic changes can cause to families due to their varying endowments and demographics. 
Explanations of structural pathways include demography. These population trains comprise, for example, the composition of the labour market, neighborhood context, age-cohort-period composition, and rural versus urban differences. All these factors influence how an economic crisis is likely to affect society and its sub-strata. For example, the impact of IMF programs is known to amplify the rural and urban divide (Babb 2005). As the IMF and government officials seek to optimize government spending, they tend to rollback available public services in remote areas. These public services tend to be costly and reach a relatively low portion of the population (Shandra et al. 2004). Therefore, there is a clear financial incentive to scale back governments' scarce resources (Daoud 2017, 2018). However, these policy actions will lead to that ruraloften less resourceful households-will experience a lowering in quality of health and educational services. Children will be less likely vaccinated (Daoud and Reinsberg 2018), and they will be less likely educated (Nielsen 2006; Rowden 2011). This has a detrimental effect on rural children's life chances. Although the rural-urban amplification hypothesis has strong theoretical support, only a few studies have tested it empirically (Daoud et al. 2017).

Political pathways: Institutions, polity, politics and public policy moderate responses to economic turmoil. Public policy can offset the increased risk that parents become unemployed following economic shocks (Mun and Jung 2018). Such policies also reduce the likelihood of material deprivation for children in the short-term. However, the IMF's primary concern when designing its programs is to balance the government's public spending with its tax revenues, in the short-term, and; to promote economic growth, in the long-run. All other issues are of secondary concern.

Thus, when the IMF encourages governments to spend less public resources, they will allocate less to social welfare (Lewis and Verhoeven 2010), education (Daoud et al. 2017), or healthcare (Stuckler and Basu 2013a). This leads to a decreased quality of services. Often quality deteriorates faster than what parents can compensate for through private spending (Heckman 2006). From a Keynesian policy perspective, fiscal spending on critical societal functions ought to be counter-cyclical (Amenta and Carruthers 1988). For example, this means that governments are encouraged to spend more on education during times of economic volatility to re-train the unemployed and prepare them when the economy improves. These countercyclical measures include social policy programs. Many governments' provide conditional cash transfer programs to keep children in school, and provide them with adequate food, and simultaneously keep them away from child labor (Nielsen 2006). However, with IMF policies in place, these types of policy tools of extra investment in education, health, and social programs, might not be available (Daoud et al. 2019). Hence, a decrease on education spending is likely to produce a detrimental effect on children's material well-being, yet the magnitude of this effect is unknown in the context of families residing in the Global South (Lewis and Verhoeven 2010; Rowden 2011).

In democracies, vulnerable families can vote for political parties favoring a generous welfare state. Power resource theory argues that families of less advantaged social classes are likely to mobilize around shared interests (Korpi and Palme 1998). These interests can include anything from forming labor unions to electing governments supporting their goals. Such governments can subsequently shape societies' policies producing cooperates institutions to provide cushioning effects during economic turmoil (Esping-Andersen 1990). For example, previous research finds that unemployed mother during a crisis increases the likelihood that children receive more care at home, especially when there are policies guaranteeing unemployment insurance (Brady and Bostic 2015). Hence, families of common interest can shape polity to their favor. Political effects are more difficult to disentangle during economic crisis since 
changing policy has a long etiological period, that is, "the length of time required by the body politics to translate coalitional cause into institutional effect” (Beckfield, 2018 p 21). Despite these difficulties, political pathways remain an essential causal factor linking shocks and material outcomes. Quantifying to what extent these pathways are moderating the link between economic crises and child poverty in the Global South remains an important research task.

\subsubsection{Linking macro and micro: the quincunx metaphor}

Macro conditions structure families' material life chances. This is especially true for the loci of institutions and policies that organize the relationship between states and markets during economic turmoil. No matter what beneficial effect parents' bring through their actions to protect their children from economic shocks, adverse societal conditions can drown these benefits. Sir Francis Galton's (1822-1911) quincunx serves as a metaphor of how life chances set by macro conditions can override families' life choices (Galton 1894; Krieger 2012). The quincunx contains a set of pegs on a board. When a perfectly shaped marble is dropped from the head of the board, each peg yields an equality likely probability that the marble travels to the right or the left. The process is repeated for many marbles. The default formation of pegs produces a normal distribution of marbles. However, small changes to the formation of pegs can produce entirely different population distributions. In the context of our study, a marble represents a child's poverty outcome; the pegs represent the macro parameters of society, and; the distribution of marbles capture the material outcome of the entire population of children.

Children are not merely physical objects driven by chance. Parents' will seek to influence their children's life chances of flowing to the left or right at each peg. In the context of IMF programs, parents will influence their children's outcomes such that they fall as close as possible to no adverse effect in the population distribution. Parents will be more or less successfulness in protecting their children because they possess different capabilities (resources). Their actions produce variations within-societies. At the same time, parents cannot directly alter the parameters of where they face each peg. The macro features of a society set these pegs. As each society has a specific formation of pegs, these produce variations between-societies (Beckfield 2018).

The quincunx metaphor provides an intuition of how IMF programs produce impact heterogeneity in children's poverty outcomes. The next section defines our research design and conceptual framework, that is, under what assumptions we intend to estimate the impact of IMF programs on child poverty.

\section{Conceptual framework: identification of IMF treatment on child poverty}

Figure 1 outlines our directed acyclic graph (DAG) that distills our conceptual framework and it clarifies our causal assumptions. Each node represents a qualitative concept. In the method section, we define how we measure each concept empirically; we measure each node of our DAG by one or more statistical variables - the data section lists these variables. A directed arrow implies a causal link. The directions of the arrows are acyclic, meaning that each causal path starting from any given node cannot terminate at the same node. It signifies, for example, that ECONOMYt-2 cannot cause itself. Dashed lines imply that the causal path is unobserved; a circle around a node implies that the node is unobserved. A node is unobserved because either we lack measurements of it or we intentionally leave them unobserved. We graph them in our DAG as they are central to our conceptual framework and modeling strategy (Morgan and Winship 2014). 
[Figure 1 about here]

Elder-Conger's family stress model specifies the causal dynamics in how family conditions affect children's material outcome. At the bottom of our DAG, we imprint the outcome of interest, CHILD POVERTY. Children's well-being ties closely to their households' LIVING CONDITIONSt $_{t}$ and to PARENT INCOMEt. We assume that LIVING CONDITIONSt are fixed-slowmoving - family characteristics that will not change during a year's period, from $t-1$ to $t$, following macroeconomic impact: AUSTERITY OF IMF PROGRAM $\mathrm{M}_{\mathrm{t}-1}$. These characteristics are, for example, whether the household is urban, how many individuals live in the household, child's age, and sex. These variables change with the state of the economic at subsequent periods, ECONOMY $\mathrm{t}_{\mathrm{t} 2}$. Conversely, PARENT INCOMEt represents fast-moving changes in parents' resources that arise due to impact. If an impact is adverse, tumultuous labor markets will cause fast-moving changes, cutting income, sharpening inequality, and soaring unemployment.

Macroeconomic impact, AUSTERITY OF IMF PROGRAM, occurs at time point $t$ - 1 . All nodes measured after this time point qualifies as post-treatment, implying it is an effect of this impact. Pre-treatment nodes, $<t-1$, are causes of impact. As our analysis aims to quantify the total effect of IMF programs, we abstain from controlling for PARENT INCOME $\mathrm{t}_{\mathrm{t}}$ as this would block some or

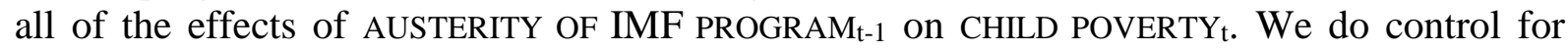
LIVING CONDITIONS t as our analysis aims to not only quantify the average IMF effect on children but also impact heterogeneity of slow-moving family characteristics. Our frameworks assume that LIVING CONDITIONSt does not lie directly on the causal path, risking to block the IMF program effect.

The red arrows represent the path of the total effect-of IMF programs on child poverty. Our framework assumes that that the shockwave of this effect propagates via two pathways, culminating at a potential impact on CHILD POVERTY. Along the first pathway lays mechanisms affecting children's parents: AUSTERITY OF IMF PROGRAM $\mathrm{t}_{\mathrm{t}-1} \rightarrow$ PUBLIC POLICY $_{t} \rightarrow$ LABOR $^{-}$ MARKET $_{t} \rightarrow$ PARENT INCOME $t \rightarrow$ CHILD POVERTY $_{t}$. PUBLIC POLICY $t$ refers to agreements that will affect the labor market. Privatization of state-owned companies or liberalization of trade, exemplifies such agreements.

Along the second pathway lays mechanisms affecting children directly via their contact with health, education and other public services: AUSTERITY OF IMF PROGRAM $\mathrm{t}_{\mathrm{t}-1} \rightarrow$ PUBLIC SPENDINGt $\rightarrow$ PUBLIC SERVICES $_{t} \rightarrow$ CHILD POVERTY $_{t}$. PUBLIC SPENDING represent governments spending allocated to public services. Children have direct encounters with the education and health systems via compulsory schooling and health visits. If these changes reduce the quality of public services, then they will force parents to use their income to compensate for the loss of quality or else their children will experience a higher risk of deprivation. However, since the beginning of the new millennia, the IMF has implemented a new social policy agenda. This agenda grants the IMF the mandate to negotiate with governments that are underspending to increase their allocation to education and health (Clements, Gupta, and Nozaki 2013; Stubbs et al. 2017). These policies can reduce child poverty. Overall, however, the aim of the IMF is to enforce the government to balance its expenses and spending. In the majority of the cases, IMF policies cause reduced social spending.

To estimate the total effect, we refrain from controlling for any of the nodes that position along these two pathways, and hence they are circled. 
Accordingly, our DAG defines the pathways-mechanisms_-via which IMF treatment effect child poverty; in synthesis with the Neyman-Rubin potential outcome framework (Imbens and Rubin 2015), this DAG aids also in defining when this effect is identified. The potential outcomes framework provides a set of helpful definitions to this end. We define IMF treatment as a binary variable, $D=1$, when a government has implemented a program, $D=0$ otherwise. Instead of taking each child's poverty outcome as a given by the data, $Y_{i}$, we imagine that each child having two potential (poverty) outcomes: when they live under the influence of a government that has implemented an IMF program, $Y_{i}(D=1)$, and without it $Y_{i}(D=0)$,

$$
\tau_{i}=Y_{i}(1)-Y_{i}(0) \text {, where } \tau \text { is the IMF impact effect for child } i \text {. }
$$

If we observed $\tau_{i}$, then we would be in a position to identify this individual-level treatment effect. However, the fundamental problem of causal inference is that we can only observe one of these outcomes for each child. Therefore, for each child, we only get to observe half of the necessary data, $Y_{i}=(D-1) Y_{i}(0)+D Y_{i}(1)$. Without strong assumptions about the datagenerating process, this individual-level treatment effect is unidentifiable. Instead, we aim to analyze $\tau_{i}$ in expectation—as-if we ran many experiments.

We specify two types of quantities of interest-estimands. First, the average treatment effect (ATE) of economic shock of IMF programs, $E\left[\tau_{i}\right]$. We analyze the direct impact of a society entering an IMF austerity program in the year before we observe a child's poverty outcome. In other words, we examine economic shocks as a society-wide event, rather than an event occurring to individual families. We quantify additional two versions of the ATE: the average treatment effect on the treated (ATT) and control (ATC). Second, we identify the most critical moderating effects sourcing from societal or family level traits. These are the conditional average treatment (impact) effect (CATE), defined in three forms: $E\left[\tau_{i} \mid \boldsymbol{X}, U, F\right]$ where $F$ is an indicator of family level variables; $E\left[\tau_{i} \mid \boldsymbol{X}, U, S\right], S$ being an indicator of structural variables; and $E\left[\tau_{i} \mid \boldsymbol{X}, U, P\right]$, where $P$ indicates political variables. The matrix $\boldsymbol{X}$ captures all other observed nodes highlighted in our DAG; $U$ represents unobserved nodes, such as POLITICAL WILLt-2.

Hence, our methodological strategy of identifying $\tau_{i}$ in expectation relies on our research designs capacity to control for, $U$. This is an untestable assumption named conditional ignorability. Our DAG highlight how governments self-selecting into IMF program threatens our identification strategy. We can block the following three backdoor paths by controlling on observables. The first backdoor path, SELECTION INTO IMFt-2 $\leftarrow$ POLITYt-2 $\leftarrow$ POLITICAL WILLt-2 $\rightarrow$ CHILD POVERTY, we block by conditioning on the observed POLITYt-2 node. The second backdoor path, SELECTION INTO IMFt-2 $\leftarrow$ PUBLIC SPENDINGt-2 $\leftarrow$ POLITICAL WILLt-2 $\rightarrow$ CHILD POVERTYt, we block by conditioning on the observed PUBLIC SPENDINGt-2 node. The third backdoor path, SELECTION INTO IMFt-2 $\leftarrow$ ECONOMYt-2 $\leftarrow$ LIVING CONDITIONSt $\rightarrow$ CHILD POVERTY $_{\mathrm{t}}$, we block by controlling for ECONOMY $\mathrm{t}_{2}$ and LIVING CONDITIONS one of these nodes are enough, but we aim to model impact heterogeneity of both of these nodes.

However, the fourth backdoor path challenges the identification strategy of only controlling on observables, SELECTION INTO IMFt-2 $\leftarrow$ POLITICAL WILLt-2 $\rightarrow$ CHILD POVERTY $_{\text {t. This }}$ path is unblocked since we cannot directly observe POLITICAL WILLt-2. It is the key unobserved factor $U$. A government's political motivation to select into a program is likely correlated with poverty 
rates in the population, which will contaminate our estimation with endogeneity. The state-ofthe-art finds that poorer societies are likely to be overrepresented in the enrolment of IMF programs (Babb 2005; Kentikelenis et al. 2016; Vreeland 2003). Although each family in our dataset did not individually cause the macroeconomic shocks in question, their collective actions cannot be viewed as independent of their government's selecting into IMF programs. They can influence polity and the economy through their collective actions, or in the absence of these actions. Thus, a naïve estimand, $\delta$, of the observed child poverty data difference, $Y$, using only $\boldsymbol{X}$ will likely be a biased.

$$
\delta=E\left[Y_{i} \mid \boldsymbol{X}, D=1\right]-E\left[Y_{i} \mid \boldsymbol{X}, D=0\right]
$$

Instead, we require an additional procedure that controls for the unobserved node, PoLITICAL WILLt-2. We posit that conditional ignorability holds given our DAG, and when blocking the

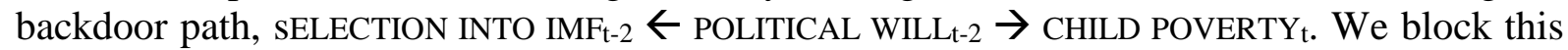
backdoor path by modeling governments' willingness to collaborate with the IMF using a Heckman selection model (Heckman 1979). We outline the statistical details of this model in the appendix. The intuition behind the Heckman model is to produce an indirect proxy for unobserved factors affecting selection. This proxy is named the INVERSE MiLL RATIO, representing $U$. We produce this proxy by modeling self-selection separately, in a first stage equation, with a Probit model. The idea is similar to a propensity score, but Heckman's model poses two additional assumptions for identification kin to an instrumental variable approach. First, it requires that the error term of the first stage is normally distributed. Second, it needs an exclusion restriction of one or several instruments that affect selection into programs but not child poverty. We rely on a commonly used instrument in the IMF literature: UN voting patterns with G7. This variable correlates with a government's decision to participate in IMF programs but do not cause the dependent variable of the outcome equation, (child poverty).

Relying on this identification strategy, we assume that ignorability holds, $Y_{i}(1), Y_{i}(0) \Perp D \mid X$, $U$, by conditioning on a proxy of POLITICAL WILL (viz. $U$ ) and key societal and individual-level features, $\boldsymbol{X}$, as outlined in our DAG.

Our last assumption is overlap. This assumption requires that the probability of receiving an IMF treatment is strictly between zero and one, $0<\operatorname{Pr}(T)<1$. Intuitively, this implies that the treatment assignment is not deterministic, or predictable. This assumption is also known as common support, implying that the joint distribution of children residing in societies with IMF program, $p_{1}(\boldsymbol{X}, U)$, is comparable to children living in societies without IMF program, $p_{0}(\boldsymbol{X}, U)$. If common support does not hold, then we cannot be guaranteed that our quasiexperiment holds. This requirement has to hold for the statistical population studied, and strictly speaking untestable in sample. An indirect measure of overlap, however, is to check whether the two distributions of propensity scores of the treated and untreated overlap. We conduct such a test in the result section.

In sum, our DAG states our identification assumptions explicitly, and thus, aids in connecting the three aspects of our research design: theoretical framework, empirical material, and statistical estimation. 


\section{Method and Data}

\subsection{Data}

\subsubsection{Micro: families and their children's living condition}

We collected household data from the Demographic and Health Survey (DHS) and the Multiple Indicator Cluster Survey (MICS). These two surveys have an identical sampling strategy and thus combinable (Corsi et al. 2012). They build on a two-stage cluster sampling process that constructs a nationally representative sample of society's living conditions. In the first stage of the sampling process, DHS and MICS statisticians define a sampling frame capturing the population stratification by a range of demographic measures. They use the latest census for that. The sampling frame enumerates a country's regions into disjunctive primary sampling units (clusters). The statisticians assign each cluster a sampling probability proportional to their population size. In the second stage of the sampling process, they then list all the households residing in each cluster. The statisticians sample about 20 to 30 households for an on-location face-to-face interview. Depending on the society's population size, the final sample varies between 4,000 to 30,000 households. The response rate tends to exceed $90 \%$. These standardized procedures generate reliable data, which enable global analyses of the sort this article aims at.

Our final household sample captures 1,940,734 children, cared for by 567,344 families, and residing in 67 societies mainly from the Global South. This sample represents about 2.8 billion ( $50 \%)$ of the world's population by the year 2000. Figure 2 highlights the sample's geographical distribution of child poverty. The living conditions of children and families are sampled once (cross-sectional), with different timing depending on DHS and MICS sampling schema. The particular surveys we collected are from around the new millennia, within a time window of five years. There are at least two advantages to analyzing data by this period. First, there is a reduced interference from global efforts to improve children's health, also affecting child poverty. After the year 2000, the global community spearheaded by the Bill and Melinda Gates Foundations have invested substantial resources in improving children's health. Second, there is a reduced interference due to changes in how IMF programs are designed. During the 1980s and 90s, the IMF encountered extensive critique from policymakers, journalists, and human rights watch groups for its austerity programs. By the late 90s, the IMF announces that it will start to accompany some of its programs with social policies, to reduce the adverse effect for vulnerable groups (IMF 2008). Focusing on the period before these policies were fully implemented purifies that direction of the effect.

[Figure 2 about here]

In the following outline, we signify nodes of our DAG with small caps; we use bold for statistical variables that measure these nodes. We extract a number of variables from the pooled DHS and MICS microdata. Table 1 highlights the balance between IMF treated children and control by central tendencies and spread of the demographics.

[Table 1 about here]

We use a deprivation-based approach to define child poverty. Contrasted with an income-based approach that measures household income, a deprivation approach measures children's access to a minimum and necessary resources. Households' income does not reveal within-family resource distributions. A deprivation approach, in contrast, provides a direct measure of need satisfaction. We rely on the Bristol method to define the deprivation dimensions and their 
thresholds. This method measures child poverty in seven dimensions (deprivations). Table 2 outlines these seven dimensions, their definitions, and empirical sample frequency. An advantage of the Bristol method compared to the Alkire-Foster approach is that Gordon et al. (2003) developed this method in collaboration with UNICEF and thus is better attuned to measuring children's living conditions globally (Alkire 2015). Hence, CHILD POVERTY is our binary indicator outcome variable. Children that are deprived on two or more of these seven dimensions are poor in absolute terms.

\section{[Table 2 about here]}

In the robustness section, we model each deprivation separately and compare the results between younger and older children splitting at age 5 . Before children reach this age, they are highly dependent on their parents. This fact bears relevance to how much of the IMF effect flows directly on to children or flows indirectly via LIVING CONDITIONS . $_{\text {. }}$

We measure children's LIVING CONDITIONSt by eight variables. We use the head of household's educational attainment. This person tends to be the individual leading the household's family affair and commonly the oldest person in the family. We use the head of household's education attainment rather than the mother's education, as the head will likely to have more influence on the choices and the behavior of the family (Randall, Coast, and Leone 2011). Educational attainment is a three-valued ordinal variable: no education, only primary, and at least secondary. We use the DHS and MICS asset-index to proxy family wealth. Surveyors sample the material living conditions of the household by counting the family's ownership of cars, bicycles, television, and other valuable commodities. Using principal component analysis, the statisticians then construct an index for each family. The rank position of each family in the pooled distribution of this index provides a proxy for how much material wealth each a family has (Rutstein 2008). We record the location of the household, whether it resides in an urban or rural area. We count the number of adults dwelling in the household where more implies an increased likelihood of additional breadwinners, and thus, that children receive proper care. We count the number of children: more children will increase families' economic burden. We also control for year of the interview to adjust for time differences. We include variables for the child's age (up to 17 years) and child's sex. Younger children are more dependent on their parents compared to older. The impact heterogeneity of IMF programs might, therefore, vary with this dependence. Likewise, due to cultural norms, parents might treat either of the sexes more favorably during economic stress.

Our analysis use Amelia II to impute missing data, for both micro and macro level. To test the robustness of the imputed data, we re-run the imputation algorithm on five different versions of the data to check the stability of our results.

\subsubsection{Macro: economy, society, and public policy}

IMF AUSTERITY PROGRAMSt-1 exposure is a binary variable. This variable indicates that the recipient government and the IMF have agreed to implement a set of policies to adjust fiscal imbalances. If the program was signed the first half of a given year, then that year signifies the starting year of a program. Otherwise, the year after it was signed will signify the starting year (Stubbs et al. 2018). SELECTED INTO IMF PROGRAM $\mathrm{t}_{\mathrm{t}-2}$ captures the POLITICAL WILLt-2 underpinning the self-selection process that we discussed in the conceptual framework section. It represents our first stage Heckman model and the set of control variables used, outlined in the appendix.

ECONOMY $\mathrm{t}_{-2}$ captures structural and demographic variables. These consist of a set of commonly used variables. GDP growth: societies with lower economic growth are more likely to become 
economically constrained, and ask for IMF credit. Current account balance: the higher the fiscal imbalance, the more likely the country is to ask for IMF help. Log GDP per capita: lowincome countries tend to seek concessional IMF assistance, whereas middle-income countries with short term economic disturbances following, for example, a currency crisis tend to ask for non-concessional loans. Trade: the sum of exports and imports of goods and services measured as a share of the gross domestic product. Economic globalization index: how integrated a nation is in the global economy will affect how many trade liberalization policies the IMF will aim to include in a program (Dreher 2006). High inflation indicator: a rapid price rise indicates structural imbalances in the economy. Negative growth: lose of GDP indicates the economic downturn. We adjust for demographic variables mainly via the microdata, but at a dependency ratio measure a societal variable that measures the combined shares of populations aged $0-14$ and 65 and above.

PUBLIC SPENDINGt-2 consists of three measures. Education spending as a percentage of total government spending, health spending as a percentage of total government spending, and total government spending. Public policies can be measured with spending measures and institutional qualitative indicators of policies (e.g., family policies, or unemployment insurance indicators) (Beckfield 2018). In the absence of institutional indicators, we selected public spending measures.

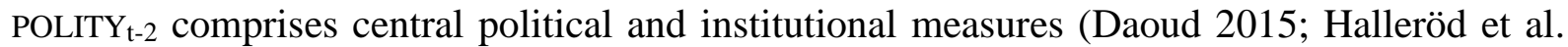
2013; Rothstein 2014). Democracy: Autocratic regimes can with less political cost invite the IMF, compared to more democratic societies. Political terror: a proxy measuring how likely social movements mobilize to change public policies. Government efficiency: an indirect measure of how effective a government is in implementing public policies. Corruption: more corruption is likely to divert resources from critical public services. Minimum age labor law: a binary variable indicating whether this law is in place regulating child labor. During economic turmoil, poorer families are more likely to let their children work. International war and Civil war: IMF avoids countries engaged in armed conflict.

\subsection{Method}

\subsubsection{Machine learning in the service of policy evaluation}

We combine a policy evaluation and machine learning methodology to estimate the impact of IMF program on child poverty. This methodology equips us with four capabilities that traditional estimation techniques lack.

The first capability: under an assumption of conditional ignorability, learning algorithms allow us to impute counterfactuals for each child, directly (Künzel et al. 2018). Matching methods can also use nonparametric techniques, but they rely instead on finding comparable cases insample (all children). Matching methods use all the covariates it is fed with, even those with low statistical relevance for the outcome. Learning algorithms, conversely, use mainly those variables that are predictive of the treatment or outcome. As long as the treated and control populations are comparable - the overlap assumption-imputing counterfactuals provides a flexible method to conduct policy evaluation of IMF programs. We capitalize on this and impute counterfactual for each child in our sample. The difference between these counterfactuals is the individual-level treatment effect, $\tau_{i}=Y_{i}(1)-Y_{i}(0)$.

The second capability: learning algorithms find impact heterogeneity inductively. Traditional regression requires from the researchers that they specify interaction variables explicitly and deductively. Researchers do so guided by theory of where they plausibly will find impact 
heterogeneity. To manage complexity, they tend to specify two-way or at most three-way interactions (Neumayer and Plümper 2017). Learning algorithms, however, suggest where impact heterogeneity is largest by analyzing the data. These algorithms then suggest a list of variables that were important in building the model. Our learning algorithm will provide such a list to identify the most important variables moderating IMF impact heterogeneity. We will organize our variables in the three key sets, following Brady's framework of poverty (Brady forthcoming): family, structural, and polity.

The third capability: learning algorithms guard against the influence of outliers, p-hacking, and cherry-picking results. Although this capability does not remove researcher discretion completely, it renders such bias to be less influential. Traditional regression procedures tend to use all the data simultaneously to generate results. Machine learning procedures, however, split the data into training and testing sets. The algorithm is first applied to the training set to find optimal regularization parameters. Then the same model is used on the testing set to estimate the quantities of interest. This procedure finds an optimal balance in the bias-variance tradeoff (Hastie, Tibshirani, and Friedman 2009). We rely on this splitting procedure to produce our results.

The fourth capability: it finds an optimal flexible functional form, $f$, given one or several selected functional classes, $\mathrm{F}$, such that $f \in \mathrm{F}$. A function class is a family of related models with distinct loss functions, auxiliary parameters, and regularization. A traditional family of functions is, for example, generalized least squares (GLM). The common loss function of GLM is mean squared error, $\sum_{j=1}^{n}\left(y_{j}-f\left(x_{j}\right)\right)^{2}$. A global estimator family is LASSO, Ridge, and elastic net. They are called global since they fit the model to the entire sample. Local estimators on the other hand fit the model to parts of the sample at a time. Decision trees, k-nearest neighbours, and random forest are example of local estimators. Combined estimators synthesize the results of several functional classes. Given a choice of a function class, the estimators evaluates which variables to use in the final model and how much weight they ought to have, given the data. It can do so as these algorithms optimize through a number of iterations by first splitting the sample into several folds. Relying on novel methodological developments in policy evaluation, we select a function class named generalize random forest (Athey, Tibshirani, and Wager 2019; Nie and Wager 2018).

\subsubsection{Generalized random forest}

Generalized random forests (grf) adapts the well-known family of random forest (RF) estimators (Breiman 2001) for efficient non-parametric estimation of causal effects (Athey et al. 2019). RF models learn ensembles of regression (or classification) trees, each fit a different resampled population and covariate set, to estimate and mitigate model variance. Each tree learns a set of rules (e.g., Age > 5) which partition the population of units into different leaves of the tree. The predicted outcome for a new unit is the average of outcomes for observed units assigned to the same leaf; the prediction of the forest is the average of the predictions of all trees. A strength of non-parametric (or machine learning) estimators such as RF is that they are designed to optimize predictive accuracy on held-out data by trading off bias and variance through regularization, rather than learning the parameters of a fixed-size model (Hastie et al. 2009). For tree-based estimators, many heuristic regularization strategies exist, including limiting the depth or number of leaf nodes in each tree. Generally, a larger number of smaller trees is preferable for out-of-sample generalization. In order to select such tuning parameters, we use sample splitting, evaluating the predictive accuracy on a randomly subsampled set of held-out data, never exposed to the model. In the case of $g r f$, it uses a version of sample splitting 
named out-of-bag predictions. As it randomly picks a subset of cases from the full samplehence, the name random forest-to grow each tree, it does not use all cases for all trees. Outof-bag prediction applies each specific case to only those trees in which the grf did not sample that case to grown those trees. This is a more efficient way to use data.

When machine learning is applied (naïvely) to causal estimation, the trade-off described above may induce regularization bias in treatment effects since minimization of predictive error is agnostic to the difference between exposure variables and covariates. For example, regularized generalized linear models tend to prefer smaller coefficients and may, therefore, bias treatment effects in either direction, depending on the correlation between treatment and covariates. To address this issue, researchers have developed so-called debiased machine learning estimators which decouple the estimation of treatment propensity and effect heterogeneity (Chernozhukov, Newey, and Robins 2018; Nie and Wager 2018). grf implement this structure through the Rlearner framework, blending regression and propensity score methods to obtain debiased estimates of causal effects (Nie and Wager 2018). The R-learner builds on the treatment effect decomposition of Robinson (1988) which relates CATE and covariates through a regression of a transformed outcome based on the observed treatment assignment. To achieve statistical efficiency, the R-learner draws on the strength of residualization, in which regressors are fit to residuals, rather than outcomes themselves. In particular, the R-learner first fits one model of treatment propensity $E[T \mid \boldsymbol{X}]$ and one of marginal effect $E[Y \mid \boldsymbol{X}]$. To obtain de-biased effect estimates, the residuals of these models are then explained by a third model - a model of the CATE with respect to $\mathrm{X}$. This approach is also called quasi-oracle estimation as it relies on fitting a model to imputations of the treatment effect for each unit.

Once an estimate of CATE-with respect to the full covariate set-has been obtained, the population may be clustered at different levels of granularity to compile average treatment effects within groups. $g r f$ uses cluster-robust errors that ensures that the standard errors are computed correctly and that they are less sensitive to outliers. In our study, the treatment-IMF programs - is assigned at the country-level. Clustered standard errors reflected this uncertainty when estimating the quantities of interest. Additionally, we may be interested in the ATE stratified only by educational level. In this case, we average CATE predictions over all individuals in each stratum, effectively coarsening our view of treatment effect heterogeneity. If the set of confounders includes more variables than education, this two-stage approach is necessary to deconfound treatment effect estimates. It has the added benefit that the CATE model does not need to be retrained if several different stratifications are of interest.

\section{Results}

\subsection{The average impact of IMF programs on child poverty}

Our generalized random forest ( $g r f$ ) estimates an adverse average treatment effect (ATE) of IMF programs on child poverty. Figure 3 highlights this effect. When a government implements an IMF program the average probability that children fall into poverty increases by 0.14 , compared to when this government abstains from it. ATE is the expected difference between each child's potential outcomes, $\tau_{i}=Y_{i}(1)-Y_{i}(0)$. Hence, $E\left[\tau_{i}\right]$. The $95 \%$ confidence interval (CI) of the ATE spans from a probability of 0.03 to 0.24 . This confidence intervals comprise robust clustered standard errors (Athey et al. 2019).

[Figure 3 about here] 
The average treatment effect on the treated (ATT) is starker than ATE. The probability that children fall into poverty during IMF programs increases to 0.24 with $95 \%$ CI, $0.02-0.46$. The ATT captures the effect of children residing in countries with an actual-observed in our dataIMF program: $E\left[\tau_{i} \mid D=1\right]$. The ATT confidence interval is wider than for ATE since there are fewer observed societies (twenty-five) with IMF programs compared to the full sample of societies (sixty-seven). The substantive difference between ATE and ATT can be comprehended with reference to the observed data. The ATE is the expected what-if difference in poverty that would be observed if we could treat a randomly selected child residing in any society but now imagining it living in both societies with and without IMF program. Conversely, the ATT is the expected what-if difference in poverty that would be observed if we treat a randomly selected child only residing in societies with IMF programs but now imagining the same two scenarios: the child living in both societies with and without IMF program. In other words, the ATT quantifies the average effect of IMF programs on child poverty of those children who reside in an society with IMF present-as observed in our data-rather than across all children living in any society (Morgan and Winship 2014:55). Following the same what-if logic, the average treatment effect on the treated (ATC) is the effect of a randomly selected child observed living in societies without IMF programs, $E\left[\tau_{i} \mid D=0\right]$, now imagined living in a society with and without these programs. The ATC is adverse with a 0.07 probability of increasing child poverty, yet smaller, and with a 95\% CI overlapping zero, $-0.05-0.18$.

[Figure 4 about here]

The histogram in Figure 4 reveals substantial impact heterogeneity. It displays the estimated effect for each child, $\tau_{i}$, in our sample $(\mathrm{n}=1,940,734)$. The blue line signifies the ATE. These individual-level effects span from beneficial impact of a probability reduction in poverty by negative 0.1 , to an increasingly adverse probability effect of 0.45 probability. The next section interrogates what aspects of our theoretical framework carries the largest moderating effect: family, structural, and political.

\subsection{Impact heterogeneity}

The quincunx metaphor conveys how life-chance (structural and political) and life-choices (family) link to influence children's probability of falling into poverty during economic crises. This metaphorical heuristic translates to what "moves" the variation of IMF program's impact heterogeneity. A key feature of machine learning in the service of policy evaluation is that these learning algorithms aid with identifying variables describing subgroups that react differently to policy changes - impact (treatment) heterogeneity. The grf algorithm is specifically devised to quantify this heterogeneity (Athey et al. 2019).

[Figure 5 about here]

While the histogram of Figure 4 shows the variation of impact heterogeneity between children, Figure 5 highlights the variation between societies. Children residing in societies experiencing the starkest adverse effect of IMF programs - for example, Tanzania, Sudan, and Lao People's Democratic Republic - have an approximately doubled probability of falling into poverty compared to the ATE represented by the blue-line. Conversely, children living in Iraq, Lesotho, and Mongolia, have zero or a slightly larger than zero probability of falling into poverty. Thus, this density plot suggests that structural and political factors-life-chances-drive a substantial part of the impact heterogeneity. 
Figure 5 also reveals substantial within-society variations of impact heterogeneity. As families within the same society are exposed to the same structural and political contextual pressure, impact heterogeneity within-society signifies a difference in families' and their children coupe with IMF impact. Our data describe mainly the resources these families' possess. Societies such as Iraq, Philippines, and Chad have large within-society variation. This implies that families in these societies have a wider range of experience in how adverse IMF programs will affect their children. Jordan and Ukraine exemplify societies with a more concentrated impact heterogeneity. This suggests that most children in such societies will experience a similar effect of IMF and poverty.

We partitioned the variance of the impact heterogeneity to quantify to what extent family traits versus societal features account for this variation. Using a multilevel random intercept null model (DiPrete and Forristal 1994), we find that 50 percent of the total impact variance sources from between-society differences and the other half arises due to differences within- and between families. ${ }^{1}$ We denote this finding as for the 50-50 impact heterogeneity rule-it corroborates the claim that both the macro (political economy) and micro (family sociology) frameworks carry equal explanatory weight in accounting for how economic turmoil affects families and their children.

[Figure 6 about here]

The $g r f$ algorithm identifies which macro and micro variables moderate most of the impact heterogeneity. Figure 6 highlights variable importance ranking. Variable importance measures how often our grf selected each variable to grow its trees. For each branch (node) split of a tree that the grf grows, the grf evaluates how much impact heterogeneity each covariate induces. The $g r f$ then selects the covariate that maximizes this heterogeneity. The variable importance metric calculates the proportion of time our grf selected a variable, counting all the branch splits.

[Figure 7 and Figure 8 about here]

Our grf identifies one of the PUBLIC SPENDINGt-2 measures-governments' education expenses - and one of the LIVING CONDITION ${ }_{t}$ measures - family wealth-moderating most of the impact heterogeneity. Family wealth has a variable importance value of 0.11 , implying that the grf selected this variable in 11 percent of all branches since it was most relevant for identifying impact heterogeneity in those branches. Figure 7 shows the conditional ATE (CATE) by family wealth quantile. Statistically, this quantity equals the conditional expectation of individual treatment effects, $E\left[\tau_{i} \mid W e a l t h_{q}\right]$, for $q$ equaling each quintile, $\{1, . ., 5\}$. The shape of these five distributions reveals that children living in households of the richest quintile (number 5) will still experience and adverse IMF impact but less so compared to any other of the remaining quintiles. Children residing in any of the three middle quintile (2 through 4 ) will experience a harsher impact than the richest and poorest (quintile 1), indicating that IMF impact hits the middle class harder than any other class.

Analogously, Figure 8 depicts how much governments' education expenses, $E\left[\tau_{i} \mid E d E x p_{q}\right]$, moderate impact heterogeneity by quintile, for $q$ quintile, $\{1, . ., 5\}$. Government of the upper quintile — those that spend most on education before they implement IMF programs—will find

\footnotetext{
${ }^{1}$ To be exact, the variance partition coefficient is $46.8 \%$ for the society level and $53.1 \%$ (1-46.8) for within society-variation.
} 
their youngest inhabitants experiencing the most adverse effects. A likely interpretation is that any government in these quintiles will have to cut their education spending, and thus, amplifying IMF impact. This interpretation gains support in what we observe in quintile 1, where governments spend the least. Although impact heterogeneity in this group is wide, and possibly bi-modal, IMF policies aid some of these children (e.g. Iraqi families) by imposing social spending floors or abstaining from cuts in public spending.

\subsection{Sensitivity analysis}

We analyzed the sensitivity of our results in seven ways. First, we estimated a new grf for each child deprivation measure, and re-calculated the quantities of interest. This exercise provides insights to which deprivation measures drives the part of the variation in child poverty that also correlates the highest with IMF programs. We find that water, shelter, and health deprivations had ATEs and ATTs different from zero at the 95\% confidence interval. Education deprivation has an ATT significant at the 90\% confidence interval. That health deprivation correlates stronger with IMF programs than education deprivation, suggest that it is more children's lack of access to vital public health services that lead to poverty more than the lack of access to schooling (Stuckler and Basu 2013b). This lack of health services can occur directly via children contact with health facilities - clinics and hospitals - or happen indirectly via the education system that also provides access to vaccines and other health related goods (Burgard and Kalousova 2015). This indirect pathway is common in the Global South (Banerjee and Duflo 2012). The provisioning of health, water, education, and to some extent shelter, all rely on public resources: that these deprivations dominate the association with IMF, corroborates the hypothesis that the causal pathway of reduced public spending carries a heavier explanatory weight than shifts in labor markets affecting parents income. See our DAG in Figure 1. Nonetheless, to exhaust fully how IMF induces treatment heterogeneity into the possible interlinkages of variances of these seven deprivation, we would need to conduct a machinelearning multinomial analysis.

Second, we conducted a permutation test, also known as a randomization test, to control for false positives, type I error (Imbens and Rubin 2015). We randomly reassigned the IMF treatment indicator, re-estimated the model, and calculate all four quantities of interest: ATE, ATT, ATE overlap, and ATC. The results of this test, outlined in Figure 9, shows that we can reject the null hypothesis for ATE; our reported effects are different from zero. The ATT permutation distributions mimics the ATE distribution, and hence, its results too are safe against type I error.

\section{[Figure 9 about here]}

Third, we re-calculated the ATE using only the intersection of the propensity distributions where treatment and control groups join. This is a test of the overlap assumption. The point estimate of the ATE-overlap, 0.132, is close to the ATE of the full sample, 0.135-rounded to three decimal points. However, the confidence interval for ATE-overlap is wider and only different from zero at a 90\% CI, 0.01-0.25.

Fourth, our analysis also varied the number of trees grown-from 1000 to 8000 trees - to check against our results being dependent on the size of the forest. The size of the forests affects the variance estimate slightly. Fewer trees induce more uncertainty, which is a statistically expected behavior (Athey et al. 2019; Breiman 2001). The quantities of interest remain stable across the size of the forests. 
Fifth, all the results we produced are estimated out-of-sample to protect against overfitting. Outof-bag estimation trained on a bootstrapped set of 4000 trees supplies an added benefit of providing some protection against researcher discretion. Given a choice of function class and a set of variables, it is more difficult to cherry-pick results.

Sixth, we tested an alternative specification of our first stage - the Heckman selection model. We added and subtracted a set of country variables that could plausibly affect our results. However, we find no significant deviations that affected our results.

Seventh, as we used Amelia II to impute missing data, we re-ran our grf on five different versions of the imputed data. We then calculated the ATE, ATT, and ATC, and compared them to the main results. The differences are negligible, demonstrating that main results are stable.

\section{Discussion}

Sociologists have in several influential studies shown the close connection between the economy and society (Smelser and Swedberg 2005), yet little is known about the impact of economic crises on children's risk of poverty in a global perspective (Grusky, Vitterna). Micro oriented studies tend to deploy the family stress model-a social psychological approach-to study the effect of economic crises on child poverty in the Global North. Macro oriented studies, fueled by debates within international political economy, tend to assemble child indicators as a proxy for aggregated societal performance during economic turmoil such as IMF programs. The present study contributes to the state-of-the-art by supplying two insights: (1) it empirically evaluates the aggregated impact of IMF programs on child poverty; (2) it analyzes the moderating effects of key societal features (life chances) and families' capabilities (life choices) in accounting for impact heterogeneity amid IMF program. In summary, our analysis has identified that IMF programs increase the probability of children residing in a randomly selected society of the Global South falling into poverty by 0.14 (95\% CI: $0.03-0.24)$ —average treatment effect (ATE). This effect is larger for children living in societies that typically have IMF programs: 0.24 (95\% CI: 0.02-0.46) —average treatment effect on the treated (ATT). We found that the variance of impact heterogeneity partitions to about $50 \%$ between societies, and 50 within them: between and within-families. We dubbed this finding the 50-50 impact moderation rule of thumb.

Our study provides at least four contributions to sociology. First, through the lens of the sociology of poverty (Brady forthcoming), our study offers a practical way to synthesized macro and micro theories. Our directed acyclic graph (DAG) explicates our assumptions of how macro and micro conditions chain into each other, subsequently forming channels via which the shockwaves of austerity can propagate and eventually land an impact on children, pushing them into poverty. The ATE and ATE are different versions of the total effect of IMF program on child poverty. Nonetheless, our learning algorithm — generalized random forest (grf)—found considerable heterogeneity distributed across these two quantities of interest. The 50-50 rule of thumb, we argue, leads us to conclude that the value of macro and micro theories are of equal importance. We recommend that future research investigate how well this rule of thumb holds in analyzing other types of economic shocks and child outcomes.

The second contribution consists of a demonstration of applied sociology. Our study showcases how sociologists, and others, can use novel methodology from computer science-machine learning in the service of policy evaluation — to inductively identify impact heterogeneity 
(Athey and Imbens 2017). Goldthorpe, among others, has recently called for a methodological framework that can capture population heterogeneity (2015:31). Our study has demonstrated how this can be achieved. Our grf — a machine-learning powered tool—enabled our analysis to identify which variables are likely to moderate most of the IMF impact heterogeneity. Traditional regression methodologies require deductive guidance of which variables to test (Western 1998).

However, learning algorithms possess the capability of finding impact heterogeneity automatically from the data (Hill 2011). This capacity enables sociologist to predict which individuals or social groups will benefit most of an event or public policy. In our case, we can formulate what-if thought experiments of what is the optimal IMF program assigned to societies, with children's well-being in mind. This included personalized (individuals) as well as socialized (populations) policy allocation (McBride and Nichols 2016). Learning algorithms, especially tree-based techniques, provide a ranked list of how important each measure is in moderating policy impact. Such a list portrays an extensive picture of what measures are the most and least important, in a given system of variables. In a linear-deductive framework, there is no equivalent to this. What scholars using this framework tend to do instead is to approximate such a list by modeling each pairwise interaction individually; but such a pair-wise analysis is different from an analysis that takes all the variables and models their $n$-pairwise interactions, simultaneously (Hastie et al. 2009).

The third contribution is that our learning algorithm suggests that family wealth is-followed closely by governments' education expenses - the highest-ranking impact moderators of all structural, political and family measures. We find that the impact of austerity affects children of the middle-strata more than the upper- and lower-stratum. This effect is comparable to what stratification research find in the Global North (Grusky et al. 2008; Redbird and Grusky 2016). Although richer families are likely to lose more of their resources in absolute terms during an economic crisis, they still have enough capabilities to shield their children from adverse effects-at least dampen this effect. Conversely, the poorest stratum tends to be worst socially and economically integrated: they tend to lack a bank account; their children are less likely to attend school or benefit from healthcare services (Garfinkel et al. 2016; Lorenz 2015). A macroeconomics shock will affect them less than if they were properly integrated. Consequently, families of the middle-stratum are those that are at greatest risk of falling victims to the shockwaves of austerity. Our analysis reveals this pattern for the Global South. Children of all strata are affected adversely, but children of the middle-class are those that are affected the worst.

The austerity mechanics of how cuts in governments' education expenses affect children in the Global South are not that different from what we expect to happen in the Global North (Grusky et al. 2011; Stuckler and Basu 2013a). For those societies that have selected into IMF programs and have historically spent most on education, will likely be at higher risk of having to reduce this spending due to austerity policies (Nielsen 2006). In the interest of balancing governments' budget, the IMF aims to reduce public spending, including health and education expenses (Babb 2005). When governments spend less on education, public schools will have fewer resources to hire teachers and result in a contraction of teachers' salaries (Rowden 2011). Consequently, this situation results in teachers having to educate more children with fewer resources, resulting in worsened schooling quality. The IMF has also promoted the enactment of tuition fees on primary education and privatizing the supply of education. This puts an additional economic burden on families. Instead of choosing to send children to relatively costly schools, parents in 
developing societies are more likely to keep them home or make them useful by sending them to work at young age (Alexander 2001).

Reducing education spending has adverse effects on children's well-being. Our analysis resonates with this pattern. A well-established fact is that early childhood development, from the brain's evolving neural connectivity to children's social capacity for empathy, is affected by environmental conditions (Heckman). This involves what children learn from their parents but also from their encounters outside the household. Their encounters and experiences in school are one of the most important social settings beside children's ties to their families. Schools are also the place where children spend most of their time when not with their families.

Additionally, reduced education spending involves fewer resources to nutritional, vaccine and direct cash transfer programs to keep children in school out of child labor (Buchmann 1996; Buchmann and Hannum 2001). In the Global South, these types of social policy programs have been crucial in lifting families and their children from deprivation (Banerjee et al. 2015). In the absence of them, children will be more likely living in poverty: undernourished and with illhealth.

The fourth contribution of our study is that it extends our sociological knowledge of economic crises and child poverty to the Global South. To this end, we assembled household data that are representative of about half the world's population. Poverty research on the United States and other rich democracies rarely engage with poverty studies in developing countries, and vice versa (Brady and Burton 2016). Although societies of the Global South offer living conditions that differ from the ones available in the Global North, our study provides an empirical window to the similarities of how children's living conditions shifts with the presence of economic turmoil. While poverty studies of rich democracies have an established research tradition focusing on social and public policies (Esping-Andersen 1999; Korpi and Palme 1998), these types of policies play an important role in the Global South as they do in the Global North. A common critique of social policy studies focusing on developing countries is that governments tend not to implement anti-poverty policies well enough (Rothstein 2014), or that corruption erodes any benefits social policies may bring (Dumas, Wedel, and Callman 2010). Therefore, studies of developing societies tend to-or should - focus instead on other proxies affecting poverty: economic development, informal economies, corruption, and institutions (Viterna and Robertson 2015). However, our findings show that more can be gained by further crossfertilizing these two research traditions, mainly divided by regional interest but not necessarily any substantive differences.

Our study has several noteworthy limitations. Our directed acyclic graph (DAG) explicates our causal assumptions-namely, ignorability. It defines how macro and micro conditions chain into each other, and subsequently, aggravate or mitigate children's probability of poverty. If, and only if, our assumptions hold in reality, then our quantities of interest are causal. This claim translates to the following question: to what extent our assumptions and modeling strategy to deal with selection bias reassure our readers. Nonetheless, definitive identification of causal effect remains challenging with observational data. Statisticians have proposed several methodological innovations to improve identification strategies, yet they often rely on untestable assumptions. In our case, the Heckman selection model relies on the excludability of instruments and normality of error terms (Fu, Winship, and Mare 2004). As outlined in the appendix, we have conducted several robustness checks to evaluate how sensitive our results are to misspecification both in the first and second stage. 
The second limitation is that our study focused on estimating the total effect of IMF programs on child poverty, and thus, did not estimate the complete mediation of paths specified in our DAG. Since the primary interest of this study is to analyze impact heterogeneity, we selected the state-of-the-art learning algorithms - grf. However, this algorithm is not optimized for mediation analysis. A grf for mediation would need to optimize both the regularization of the treatment variable and the mechanism (Pearl 2012; VanderWeele 2015). Thus, this is an exciting task for future research-both developing the algorithm and to apply it.

The third limitation refers to the fact that our study evaluated the impact of IMF programs as a homogenous package of policies. Scholars have shown that the type and number of policies per programs vary depending on where they are implemented (Kentikelenis et al. 2016). Some programs contain more privatization policies that will likely affect the supply of public schools, compared to programs with fewer such policies. Related to this limitation, our broader motivation of this study was to study the impact of economic crises on child poverty. We focused on IMF programs-following Merton's (1987) advice on selecting strategic research case-since these programs are the focus of extensive literature in political economy. However, more research is required to compare the effect of these programs to other types of crises, such as currency cries, bank crises, and sovereign debt crises where governments opt for abstaining from IMF support (Redbird and Grusky 2016; Reinhart and Rogoff 2008).

In conclusion, although governments-under the supervision of the IMF-may stabilize sovereign debt crises in the short run, the increased number of children that will fall into poverty from the middle class will likely produce economic and social instabilities in the long-run (Babb 2005). In this case, policymakers face a trade-off: shall they cut public spending to mitigate fiscal deficits, or shall they keep their investments in public services saving children. This tradeoff has no simple answer. Yet, investing in children's early life is as much an investment in future lives as an investment in public resources; both economists (Heckman 2006) and sociologist (McLanahan and Percheski 2008) agree with this claim. 


\section{References}

Abbott, Andrew. 1988. “Transcending General Linear Reality.” Sociological Theory 6(2):169-86.

Alexander, Nancy C. 2001. "Paying for Education: How the World Bank and the International Monetary Fund Influence Education in Developing Countries.” Peabody Journal of Education 76(3-4):285-338.

Alkire, Sabina. 2015. Multidimensional Poverty Measurement and Analysis. First edition. Oxford: Oxford University Press.

Amenta, Edwin and Bruce G. Carruthers. 1988. "The Formative Years of U.S. Social Spending Policies: Theories of the Welfare State and the American States During the Great Depression.” American Sociological Review 53(5):661-78.

Athey, Susan and Guido W. Imbens. 2017. "The State of Applied Econometrics: Causality and Policy Evaluation.” Journal of Economic Perspectives 31(2):3-32.

Athey, Susan, Julie Tibshirani, and Stefan Wager. 2019. “Generalized Random Forests.” The Annals of Statistics 47(2):1148-78.

Aytaç, Işik A. and Bruce H. Rankin. 2009. "Economic Crisis and Marital Problems in Turkey: Testing the Family Stress Model.” Journal of Marriage and Family 71(3):756-67.

Ayuso-Mateos, J. L., Pedro Pita Barros, and R. Gusmao. 2013. "Financial Crisis, Austerity, and Health in Europe.” The Lancet 382(9890):391-92.

Babb, Sarah. 2005. "The Social Consequences of Structural Adjustment: Recent Evidence and Current Debates.” Annual Review of Sociology 31:199-222.

Babb, Sarah L. and Bruce G. Carruthers. 2008. "Conditionality: Forms, Function, and History.” Annual Review of Law and Social Science 4(1):13-29.

Baird, Sarah, Jed Friedman, and Norbert Schady. 2010. “Aggregate Income Shocks and Infant Mortality in the Developing World.” The Review of Economics and Statistics 93(3):847-56.

Bal Gündüz, Yasemİn. 2016. "The Economic Impact of Short-Term IMF Engagement in Low-Income Countries.” World Development 87(Vol. 87 - 2016):30-49.

Banerjee, Abhijit and Esther Duflo. 2012. Poor Economics: A Radical Rethinking of the Way to Fight Global Poverty. Reprint edition. New York: PublicAffairs.

Banerjee, Abhijit, Esther Duflo, Nathanael Goldberg, Dean Karlan, Robert Osei, William Parienté, Jeremy Shapiro, Bram Thuysbaert, and Christopher Udry. 2015. “A Multifaceted Program Causes Lasting Progress for the Very Poor: Evidence from Six Countries.” Science 348(6236):1260799.

Basu, Sanjay, David Stuckler, Martin McKee, and Gauden Galea. 2013. "Nutritional Determinants of Worldwide Diabetes: An Econometric Study of Food Markets and Diabetes Prevalence in 173 Countries - Corrigendum.” Public Health Nutrition 16(01):189-189. 
Beckfield, Jason. 2018. Political Sociology and the People's Health. Oxford, UNITED STATES: Oxford University Press USA - OSO.

Belloni, A., V. Chernozhukov, I. Fernández-Val, and C. Hansen. 2017. "Program Evaluation and Causal Inference With High-Dimensional Data.” Econometrica 85(1):233-98.

Benatar, Solomon R., Stephen Gill, and Isabella Bakker. 2011. "Global Health and the Global Economic Crisis.” American Journal of Public Health 101(4):646-53.

Bermeo, Nancy and Jonas Pontusson. 2012. Coping with Crisis: Government Reactions to the Great Recession. Russell Sage Foundation.

Bertrand, Marianne, Sendhil Mullainathan, and Eldar Shafir. 2004. "A Behavioral-Economics View of Poverty.” American Economic Review 419-423.

Boss, Pauline, Chalandra M. Bryant, and Jay A. Mancini. 2016. Family Stress Management: A Contextual Approach. Sage Publications.

Bradshaw, J. 2000. "Child Poverty in a Comparative Perspective.” in Breadline Europe: The Measurement of Poverty, edited by D. Gordon and P. Townsend. Bristol: The Policy Press.

Brady, David. forthcoming. "Theories of the Causes of Poverty.” Annual Review of Sociology 38.

Brady, David. 2005. "The Welfare State and Relative Poverty in Rich Western Democracies, 1967-1997.” Social Forces 83(4):1329-64.

Brady, David, Agnes Blome, and Hanna Kleider. 2016. "How Politics and Institutions Shape Poverty and Inequality.” The Oxford Handbook of the Social Science of Poverty 117.

Brady, David and Amie Bostic. 2015. "Paradoxes of Social Policy: Welfare Transfers, Relative Poverty, and Redistribution Preferences.” American Sociological Review 80(2):268-98.

Brady, David and Linda M. Burton. 2016. “Introduction.” 19.

Breiman, Leo. 2001. "Random Forests.” Machine Learning 45(1):5-32.

Buchmann, Claudia. 1996. "The Debt Crisis, Structural Adjustment and Women’s Education.” International Journal of Comparative Sociology 37(1):5-30.

Buchmann, Claudia and Emily Hannum. 2001. "Education and Stratification in Developing Countries: A Review of Theories and Research.” Annual Review of Sociology 27(1):77-102.

Burgard, Sarah A. and Lucie Kalousova. 2015. "Effects of the Great Recession: Health and Well-Being.” Annual Review of Sociology 41(1):1-21.

Butkiewicz, James L. and Halit Yanikkaya. 2005. "The Effects of IMF and World Bank Lending on Long-Run Economic Growth: An Empirical Analysis.” World Development 33(3):371-91. 
Cherlin, Andrew J. 2012. "Goode’s World Revolution and Family Patterns: A Reconsideration at Fifty Years.” Population and Development Review 38(4):577-607.

Chernozhukov, Victor, Whitney Newey, and James Robins. 2018. "Double/De-Biased Machine Learning Using Regularized Riesz Representers.” ArXiv:1802.08667 [Econ, Math, Stat].

Claessens, Stijn, Giovanni Dell’Ariccia, Deniz Igan, and Luc Laeven. 2010. "Cross-Country Experiences and Policy Implications from the Global Financial Crisis.” Economic Policy 25(62):267-293.

Clements, Benedict, Sanjeev Gupta, and Masahiro Nozaki. 2013. "What Happens to Social Spending in IMF-Supported Programmes?” Applied Economics 45(28):4022-33.

Cline, William R. 2004. Trade Policy and Global Poverty. Washington, DC.: Institute for International Economics :

Conger, Rand D., Katherine J. Conger, Glen H. Elder, Frederick O. Lorenz, Ronald L. Simons, and Les B. Whitbeck. 1992. "A Family Process Model of Economic Hardship and Adjustment of Early Adolescent Boys.” Child Development 63(3):526-41.

Conger, Rand D., Katherine J. Conger, and Monica J. Martin. 2010. “Socioeconomic Status, Family Processes, and Individual Development.” Journal of Marriage and Family 72(3):685-704.

Conger, Rand D. and M. Brent Donnellan. 2007. “An Interactionist Perspective on the Socioeconomic Context of Human Development.” Annual Review of Psychology 58(1):175-99.

Conklin, Annalijn I., Adel Daoud, Riti Shimkhada, and Ninez A. Ponce. 2018. "The Impact of Rising Food Prices on Obesity in Women: A Longitudinal Analysis of 31 LowIncome and Middle-Income Countries from 2000 to 2014.” International Journal of Obesity 1.

Conley, Dalton and Kristen W. Springer. 2001. "Welfare State and Infant Mortality.” American Journal of Sociology 107(3):768-807.

Cornia, Giovanni Andrea, Richard Jolly, and Frances Stewart. 1987. Adjustment with a Human Face. Vol. 1, Protecting the Vulnerable and Promoting Growth. Oxford: Clarendon.

Corsi, Daniel J., Melissa Neuman, Jocelyn E. Finlay, and S. V. Subramanian. 2012. "Demographic and Health Surveys: A Profile.” International Journal of Epidemiology 41(6):1602-13.

Daoud, Adel. 2015. "Quality of Governance, Corruption, and Absolute Child Poverty in India.” Journal of South Asian Development 10(2):1-20.

Daoud, Adel. 2017. "Synthesizing the Malthusian and Senian Approaches on Scarcity: A Realist Account.” Cambridge Journal of Economics 42(2):453-76. 
Daoud, Adel. 2018. “Unifying Studies of Scarcity, Abundance, and Sufficiency.” Ecological Economics 147:208-17.

Daoud, Adel, Elias Nosrati, Bernhard Reinsberg, Alexander E. Kentikelenis, Thomas H. Stubbs, and Lawrence P. King. 2017. "Impact of International Monetary Fund Programs on Child Health.” Proceedings of the National Academy of Sciences 114(25):6492-97.

Daoud, Adel and Goran Puaca. 2011. “An Organic View of Students’ Want Formation: Pragmatic Rationality, Habitus and Reflexivity.” British Journal of Sociology of Education 32(4):603-22.

Daoud, Adel and Bernhard Reinsberg. 2018. "Structural Adjustment, State Capacity and Child Health: Evidence from IMF Programmes.” International Journal of Epidemiology dyy251:1-10.

Daoud, Adel, Bernhard Reinsberg, Alexander E. Kentikelenis, Thomas H. Stubbs, and Lawrence P. King. 2019. “The International Monetary Fund's Interventions in Food and Agriculture: An Analysis of Loans and Conditions.” Food Policy.

Desmond, Matthew. 2012. “Disposable Ties and the Urban Poor.” American Journal of Sociology 117(5):1295-1335.

Desmond, Matthew and Bruce Western. 2018. "Poverty in America: New Directions and Debates.” Annual Review of Sociology 44(1):305-18.

DiPrete, Thomas A. and Jerry D. Forristal. 1994. "Multilevel Models: Methods and Substance.” Annual Review of Sociology 20:331-57.

Dobbin, Frank R. 1993. “The Social Construction of the Great Depression: Industrial Policy during the 1930s in the United States, Britain, and France.” Theory and Society 22(1):1-56.

Dreher, Axel. 2006. "Does Globalization Affect Growth? Evidence from a New Index of Globalization.” Applied Economics 38(10):1091-1110.

Dumas, Lloyd J., Janine R. Wedel, and Greg Callman. 2010. Confronting Corruption, Building Accountability: Lessons from the World of International Development Advising. New York: Palgrave Macmillan.

Durkheim, Émile. 1979. Suicide: A Study in Sociology. Repr. London: Routledge.

Elder, Glen H. 1998. Children Of The Great Depression: 25th Anniversary Edition. 25th Anniversary, Updated edition. Westview Press.

Esping-Andersen, Gøsta. 1990. The Three Worlds of Welfare Capitalism. Princeton, N.J.: Princeton University Press.

Esping-Andersen, Gøsta. 1999. Social Foundations of Postindustrial Economies. New York: Oxford University Press. 
Ferraro, Kenneth F., Markus H. Schafer, and Lindsay R. Wilkinson. 2016. “Childhood Disadvantage and Health Problems in Middle and Later Life: Early Imprints on Physical Health?” American Sociological Review 81(1):107-33.

Fu, Vincent Kang, Christopher Winship, and Robert D. Mare. 2004. "Sample Selection Bias Models.” Pp. 408-30 in Handbook of Data Analysis. 1 Oliver's Yard, 55 City Road, London England EC1Y 1SP United Kingdom: SAGE Publications, Ltd.

Galton, Francis. 1894. Natural Inheritance. Macmillan and Company.

Garfinkel, Irwin, Sara McLanahan, and Christopher Wimer. 2016. Children of the Great Recession. New York: Ruseel Sage Foundation.

Gibson-Davis, Christina M., Kathryn Edin, and Sara McLanahan. 2005. "High Hopes but Even Higher Expectations: The Retreat From Marriage Among Low-Income Couples.” Journal of Marriage and Family 67(5):1301-12.

Gkiouleka, Anna, Tim Huijts, Jason Beckfield, and Clare Bambra. 2018. "Understanding the Micro and Macro Politics of Health: Inequalities, Intersectionality \& Institutions - A Research Agenda.” Social Science \& Medicine 200:92-98.

Goldthorpe, John H. 2015. Sociology as a Population Science. Cambridge University Press.

Gordon, David, Shailen Nandy, Christina Pantazis, Simon Pemberton, and Peter Townsend. 2003. Child Poverty in the Developing World. Bristol, UK: Polity Press.

Grimmer, Justin, Solomon Messing, and Sean J. Westwood. 2017. “Estimating Heterogeneous Treatment Effects and the Effects of Heterogeneous Treatments with Ensemble Methods.” Political Analysis 25(4):413-34.

Grusky, David B., Manwai C. Ku, and Szonja Szelényi, eds. 2008. Social Stratification: Class, Race, and Gender in Sociological Perspective. 3rd ed. Boulder, Colo: Westview Press.

Grusky, David B., Bruce Western, and Christopher Wimer. 2011. The Great Recession. Russell Sage Foundation.

Hall, Peter A. and Michèle Lamont, eds. 2009. Successful Societies: How Institutions and Culture Affect Health. 1 edition. New York: Cambridge University Press.

Halleröd, Björn, Bo Rothstein, Adel Daoud, and Shailen Nandy. 2013. "Bad Governance and Poor Children: A Comparative Analysis of Government Efficiency and Severe Child Deprivation in 68 Low-and Middle-Income Countries.” World Development 48:19-31.

Halliday, Terence C. and Bruce G. Carruthers. 2009. Bankrupt: Global Lawmaking and Systemic Financial Crisis. Stanford: Stanford University Press.

Hamm, Patrick, Lawrence P. King, and David Stuckler. 2012. "Mass Privatization, State Capacity, and Economic Growth in Post-Communist Countries.” American Sociological Review 77(2):295-324. 
Hastie, Trevor, Robert Tibshirani, and Jerome Friedman. 2009. The Elements of Statistical Learning. 2 edition. Springer New York.

Heckman, James J. 1979. “Sample Selection Bias as a Specification Error.” Econometrica 47(1):153-61.

Heckman, James J. 2006. "Skill Formation and the Economics of Investing in Disadvantaged Children.” Science 312(5782):1900-1902.

Hill, Jennifer L. 2011. "Bayesian Nonparametric Modeling for Causal Inference.” Journal of Computational and Graphical Statistics 20(1):217-40.

Hraba, Joseph, Frederick O. Lorenz, and Zdeňka Pechačová. 2000. "Family Stress During the Czech Transformation.” Journal of Marriage and Family 62(2):520-31.

IEO. 2003. Fiscal Adjustment in IMF-Supported Programs. Washington DC: IMF Independent Evaluation Office.

Imbens, Guido W. and Donald B. Rubin. 2015. Causal Inference for Statistics, Social, and Biomedical Sciences: An Introduction. 1 edition. New York: Cambridge University Press.

IMF. 2008. “IMF Helping Countries on Health, Social Spending Policies.” International Monetary Fund. Retrieved (https://www.imf.org/external/pubs/ft/survey/so/2008/POL072508A.htm).

Jenkins, Stephen P., Andrea Brandolini, John Micklewright, and Brian Nolan, eds. 2012. The Great Recession and the Distribution of Household Income. Oxford Univ Press.

Johansson, Fredrik, Uri Shalit, and David Sontag. 2016. "Learning Representations for Counterfactual Inference.” Pp. 3020-3029 in International Conference on Machine Learning.

Kentikelenis, Alexander E., Thomas H. Stubbs, and Lawrence P. King. 2016. "IMF Conditionality and Development Policy Space, 1985-2014.” Review of International Political Economy (Online first).

Kindleberger, Charles P. and Robert Z. Aliber. 2011. Manias, Panics, and Crashes: A History of Financial Crises. New York: Palgrave Macmillan.

Kinnunen, Ulla and Taru Feldt. 2004. "Economic Stress and Marital Adjustment among Couples: Analyses at the Dyadic Level.” European Journal of Social Psychology 34(5):519-32.

Korpi, Walter and Joachim Palme. 1998. “The Paradox of Redistribution and Strategies of Equality: Welfare State Institutions, Inequality, and Poverty in the Western Countries.” American Sociological Review 63(5):6661-87.

Kraamwinkel, Nadine, Hans Ekbrand, Stefania Davia, and Adel Daoud. 2019. “The Influence of Maternal Agency on Severe Child Undernutrition in Conflict-Ridden Nigeria: Modeling Heterogeneous Treatment Effects with Machine Learning.” PLOS ONE 14(1):e0208937. 
Krieger, Nancy. 2012. “Who and What Is a 'Population'? Historical Debates, Current Controversies, and Implications for Understanding 'Population Health’ and Rectifying Health Inequities.” Milbank Quarterly 90(4):634-81.

Künzel, Sören R., Jasjeet S. Sekhon, Peter J. Bickel, and Bin Yu. 2018. “Meta-Learners for Estimating Heterogeneous Treatment Effects Using Machine Learning." ArXiv:1706.03461 [Math, Stat].

Kwak, I. S., Y. S. Song, and K. A. Kim. 1999. "The Financial Crisis Effects on the Family Life-a Comparison between before and after IMF.” Journal of Korean Home Economics Association 17:121-37.

Kwon, Hee-Kyung, Martha A. Rueter, Mi-Sook Lee, Seonju Koh, and Sun Wha Ok. 2003. "Marital Relationships Following the Korean Economic Crisis: Applying the Family Stress Model.” Journal of Marriage and Family 65(2):316-25.

Laeven, Luc and Fabián Valencia. 2013. “Systemic Banking Crises Database.” IMF Economic Review 61(2):225-70.

Laub, John H. and Robert J. Sampson. 2009. Shared Beginnings, Divergent Lives. Harvard University Press.

Leininger, Lindsey Jeanne and Ariel Kalil. 2014. "Economic Strain and Children's Behavior in the Aftermath of the Great Recession.” Journal of Marriage and Family 76(5):9981010 .

Lewis, Maureen and Marijn Verhoeven. 2010. "Financial Crises and Social Spending: The Impact of the 2008-2009 Crisis.” World Economics 11(4):79-110.

Lorenz, Stephan. 2015. “Having No Choice: Social Exclusion in the Affluent Society.” Journal of Exclusion Studies 5(1):1.

McBride, Linden and Austin Nichols. 2016. "Retooling Poverty Targeting Using Out-ofSample Validation and Machine Learning.” The World Bank Economic Review.

McLanahan, Sara. 2009. "Fragile Families and the Reproduction of Poverty." The ANNALS of the American Academy of Political and Social Science 621(1):111-31.

McLanahan, Sara and Christine Percheski. 2008. "Family Structure and the Reproduction of Inequalities.” Annual Review of Sociology 34(1):257-76.

McLeod, Jane D. and Michael J. Shanahan. 1993. "Poverty, Parenting, and Children’s Mental Health.” American Sociological Review 58(3):351-66.

McLoyd, Vonnie C. 1998. “Socioeconomic Disadvantage and Child Development.” American Psychologist 53(2):185-204.

McLoyd, Vonnie C., Rosanne M. Jocson, and Abigail B. Williams. 2017. Linking Poverty and Children's Development. Vol. 1. edited by D. Brady and L. M. Burton. Oxford University Press. 
Merton, Robert K. 1987. “Three Fragments from a Sociologist's Notebooks: Establishing the Phenomenon, Specified Ignorance, and Strategic Research Materials.” Annual Review of Sociology 13:1-28.

Mitchell, Colter, Sara McLanahan, John Hobcraft, Jeanne Brooks-Gunn, Irwin Garfinkel, and Daniel Notterman. 2015. "Family Structure Instability, Genetic Sensitivity, and Child Well-Being.” American Journal of Sociology 120(4):1195-1225.

Morgan, Stephen L. and Christopher Winship. 2014. Counterfactuals and Causal Inference: Methods and Principles for Social Research. 2 edition. New York, NY: Cambridge University Press.

Moser, Christoph and Jan-Egbert Sturm. 2011. "Explaining IMF Lending Decisions after the Cold War.” The Review of International Organizations 6(3-4):307-40.

Mullainathan, Sendhil and Jann Spiess. 2017. "Machine Learning: An Applied Econometric Approach.” Journal of Economic Perspectives 31(2):87-106.

Mun, Eunmi and Jiwook Jung. 2018. "Policy Generosity, Employer Heterogeneity, and Women's Employment Opportunities: The Welfare State Paradox Reexamined." American Sociological Review 83(3):508-35.

Nandy, Shailen, Adel Daoud, and David Gordon. 2016. "Examining the Changing Profile of Undernutrition in the Context of Food Price Rises and Greater Inequality.” Social Science \& Medicine 149:153-63.

Neumayer, Eric and Thomas Plümper. 2017. Robustness Tests for Quantitative Research. Cambridge, United Kingdom; New York, NY, USA: Cambridge University Press.

Nie, Xinkun and Stefan Wager. 2018. "Quasi-Oracle Estimation of Heterogeneous Treatment Effects.” ArXiv:1712.04912 [Econ, Math, Stat].

Nielsen, H. Dean. 2006. From Schooling Access to Learning Outcomes: An Unfinished Agenda: An Evaluation of World Bank Support to Primary Education. Washington D.C.: World Bank Independent Evaluation Group.

Owens, Ann. 2016. "Inequality in Children’s Contexts: Income Segregation of Households with and without Children.” American Sociological Review 81(3):549-74.

Pearl, Judea. 2012. “The Causal Foundations of Structural Equation Modeling.” P. 740 in Handbook of Structural Equation Modeling, edited by R. H. Hoyle. New York: The Guilford Press.

Ponce, Ninez, Riti Shimkhada, Amy Raub, Adel Daoud, Arijit Nandi, Linda Richter, and Jody Heymann. 2017. "The Association of Minimum Wage Change on Child Nutritional Status in LMICs: A Quasi-Experimental Multi-Country Study.” Global Public Health 0(0):1-15.

Pontusson, Jonas and Damian Raess. 2012. "How (and Why) Is This Time Different? The Politics of Economic Crisis in Western Europe and the United States.” Annual Review of Political Science 15(1):13-33. 
Puaca, Goran and Adel Daoud. 2011. "Vilja Och Framtid i Frågor Kring Utbildningsval.” Pedagogisk Forskning i Sverige 16(2):100.

Ragin, Charles C. 2008. Redesigning Social Inquiry: Fuzzy Sets and Beyond. University Of Chicago Press.

Ramesh, M. 2009. "Economic Crisis and Its Social Impacts Lessons from the 1997 Asian Economic Crisis.” Global Social Policy 9(1 suppl):79-99.

Randall, Sara, Ernestina Coast, and Tiziana Leone. 2011. "Cultural Constructions of the Concept of Household in Sample Surveys.” Population Studies 65(2):217-29.

Ravallion, Martin. 2015. The Economics of Poverty: History, Measurement, and Policy. 1 edition. Oxford University Press.

Redbird, Beth and David B. Grusky. 2016. "Distributional Effects of the Great Recession: Where Has All the Sociology Gone?” Annual Review of Sociology 42(1):185-215.

Reinhart, Carmen M. and Kenneth S. Rogoff. 2008. This Time Is Different: A Panoramic View of Eight Centuries of Financial Crises. National Bureau of Economic Research.

Robinson, P. M. 1988. “Root-N-Consistent Semiparametric Regression.” Econometrica 56(4):931-54.

Rothstein, Bo. 2014. "The Chinese Paradox of High Growth and Low Quality of Government: The Cadre Organization Meets Max Weber.” Governance.

Rowden, Rick. 2011. Impacts of IMF Policies on National Education Budgets and Teachers. Brussels: Education International Research Institute.

Rutstein, S. O. 2008. The DHS Wealth Index: Approaches for Rural and Urban Areas. popline.org.

Schneider, Daniel, Orestes P. Hastings, and Joe LaBriola. 2018. "Income Inequality and Class Divides in Parental Investments.” American Sociological Review 83(3):475-507.

Schneider, William, Jane Waldfogel, and Jeanne Brooks-Gunn. 2015. “The Great Recession and Behavior Problems in 9-Year Old Children.” Developmental Psychology 51(11):1615-29.

Sen, Amartya. 1999. Development as Freedom. New York: Alfred A. Knopf.

Shandra, Carrie L., John M. Shandra, and Bruce London. 2011. "World Bank Structural Adjustment, Water, and Sanitation: A Cross-National Analysis of Child Mortality in Sub-Saharan Africa.” Organization \& Environment 24(2):107-29.

Shandra, Carrie L., John M. Shandra, and Bruce London. 2012. "The International Monetary Fund, Structural Adjustment, and Infant Mortality: A Cross-National Analysis of SubSaharan Africa.” Journal of Poverty 16(2):194-219. 
Shandra, John M., Jenna Nobles, Bruce London, and John B. Williamson. 2004. "Dependency, Democracy, and Infant Mortality: A Quantitative, Cross-National Analysis of Less Developed Countries.” Social Science \& Medicine 59(2):321-33.

Smelser, Neil J. and Richard Swedberg. 2005. “Introducing Economic Sociology.” Pp. ix, 736 $\mathrm{s}$ in The handbook of economic sociology, edited by N. J. Smelser and R. Swedberg. Princeton, New York: Princeton Univ. Press,.

Sosnaud, Benjamin and Jason Beckfield. 2017. "Trading Equality for Health? Evaluating the Trade-off and Institutional Hypotheses on Health Inequalities in the Global South.” Journal of Health and Social Behavior 58(3):340-56.

Straus, Murray A., Richard J. Gelles, and Suzanne K. Steinmetz. 1980. "Behind Closed Doors: Violence in American Families.” Garden City, NY: Anchor/Doubleday.

Stubbs, Thomas and Alexander Kentikelenis. 2018. "Targeted Social Safeguards in the Age of Universal Social Protection: The IMF and Health Systems of Low-Income Countries.” Critical Public Health 28(2):132-39.

Stubbs, Thomas, Alexander Kentikelenis, David Stuckler, Martin McKee, and Lawrence King. 2017. "The Impact of IMF Conditionality on Government Health Expenditure: A Cross-National Analysis of 16 West African Nations.” Social Science \& Medicine 174:220-27.

Stubbs, Thomas, Bernhard Reinsberg, Alexander Kentikelenis, and Lawrence King. 2018. "How to Evaluate the Effects of IMF Conditionality." The Review of International Organizations.

Stuckler, David and Sanjay Basu. 2013a. The Body Economic: Eight Experiments in Economic Recovery, from Iceland to Greece. London: Allen Lane.

Stuckler, David and Sanjay Basu. 2013b. The Body Economic: Why Austerity Kills : Recessions, Budget Battles, and the Politics of Life and Death.

Stuckler, David, Lawrence P. King, and Sanjay Basu. 2008. “International Monetary Fund Programs and Tuberculosis Outcomes in Post-Communist Countries" edited by M. Murray. PLoS Medicine 5(7):e143.

Swedberg, Richard. 2013. "The Financial Crisis in the US 2008-2009: Losing and Restoring Confidence.” Socio-Economic Review 11(3):501-523.

Teorell, Jan, Stefan Dahlberg, Holmberg Sören, Rothstein Bo, Natalia Alvarado Pachon, and Richard Svensson. 2018. The Quality of Government Standard Dataset, Version Jan18. University of Gothenburg. The Quality of Government Institute.

Thomson, Michael, Alexander Kentikelenis, and Thomas Stubbs. 2017. "Structural Adjustment Programmes Adversely Affect Vulnerable Populations: A SystematicNarrative Review of Their Effect on Child and Maternal Health." Public Health Reviews 38:13. 
Tomaskovic-Devey, Donald. 1991. "A Structural Model of Poverty Creation and Change: Political Economy, Local Opportunity, and US Poverty, 1959-1979.” Research in Social Stratification and Mobility 10:289-322.

Townsend, Peter. 1987. “Deprivation.” Journal of Social Policy 16(02):125-146.

VanderWeele, Tyler. 2015. Explanation in Causal Inference: Methods for Mediation and Interaction. Oxford, New York: Oxford University Press.

Viterna, Jocelyn and Cassandra Robertson. 2015. "New Directions for the Sociology of Development.” Annual Review of Sociology 41(1):243-69.

Vreeland, James Raymond. 2003. The IMF and Economic Development. New York: Cambridge University Press.

Vreeland, James Raymond. 2007. The International Monetary Fund: Politics of Conditional Lending. New York, NY: Routledge, Taylor \& Francis Group.

Wacquant, Loïc. 2009. Punishing the Poor: The Neoliberal Government of Social Insecurity. First edition, paperback issue edition. Durham NC: Duke University Press Books.

Weber, Max. 1949. The Methodology of the Social Sciences. New York: Free Press.

Western, Bruce. 1998. “Causal Heterogeneity in Comparative Research: A Bayesian Hierarchical Modelling Approach.” American Journal of Political Science 42(4):1233-59.

Western, Bruce. 2002. “The Impact of Incarceration on Wage Mobility and Inequality.” American Sociological Review 67(4):526-46.

WHO. 2013. Global Vaccine Action Plan: 2011-2020. Geneva, Switzerland: World Health Organization Press.

Williamson, John. 1990. "What Washington Means by Policy Reform.” in Latin American Adjustment: How Much Has Happened?, edited by J. Williamson. Washington DC: Peterson Institute for International Economics.

Wood, Joanne N., Sheyla P. Medina, Chris Feudtner, Xianqun Luan, Russell Localio, Evan S. Fieldston, and David M. Rubin. 2012. "Local Macroeconomic Trends and Hospital Admissions for Child Abuse, 2000-2009.” Pediatrics 130(2):e358-64.

Xie, Yu. 2013. "Population Heterogeneity and Causal Inference.” Proceedings of the National Academy of Sciences 201303102.

\section{Tables}

Table 1. Descriptive demographics stratified by IMF treatment status

$\mathrm{IMF}=0 \quad \mathrm{IMF}=1$




\begin{tabular}{lll}
\hline \multicolumn{1}{c}{$\mathrm{n}$} & 985805 & 955929 \\
Child_age (mean (sd)) & $8.27(5.06)$ & $8.08(5.07)$ \\
Child_sex = Male (\%) & $501117(50.8)$ & $483457(50.6)$ \\
Urban_household = rural (\%) & $613439(62.2)$ & $603594(63.1)$ \\
Family_wealth (\%) & & \\
\multicolumn{1}{c}{ ( 1} & $256662(26.0)$ & $223967(23.4)$ \\
$\quad 3$ & $192713(19.5)$ & $192630(20.2)$ \\
$\quad$ 5 & $187835(19.1)$ & $190872(20.0)$ \\
Nr_of_children (mean (sd)) & $170723(17.3)$ & $173794(18.2)$ \\
Nr_of_adults (mean (sd)) & $177872(18.0)$ & $174666(18.3)$ \\
Head_education (\%) & $3.77(2.44)$ & $4.04(3.21)$ \\
noEducation & $2.91(1.87)$ & $2.97(2.42)$ \\
Primary & & \\
SecondaryPlus & $314602(31.9)$ & $273742(28.6)$ \\
Year_of_interview (mean (sd)) & $360369(36.6)$ & $330722(34.6)$ \\
Health_spending (mean (sd)) & $310834(31.5)$ & $351465(36.8)$ \\
Democracy (mean (sd)) & $8.32(5.61)$ & $10.03(3.51)$ \\
Trade (mean (sd)) & $5.12(3.23)$ & $5.89(2.01)$ \\
Expenses_balance (mean (sd)) & $66.07(39.99)$ & $56.73(27.38)$ \\
Economic_develop (mean (sd)) & $-2.29(6.31)$ & $-3.40(2.79)$ \\
War (mean (sd)) & $6.51(0.86)$ & $6.09(0.85)$ \\
Dependency_ratio (mean (sd)) & $0.13(0.80)$ & $0.21(0.90)$ \\
Negative_growth (mean (sd)) & $76.07(11.95)$ & $80.31(12.89)$ \\
Inflation (mean (sd)) & $6.99(6.82)$ & $5.04(2.58)$ \\
Political_will (mean (sd)) & $0.10(0.29)$ & $0.05(0.22)$ \\
Education_spending (mean (sd)) & $-0.42(0.49)$ & $0.27(0.20)$ \\
Economic_globalization (mean (sd)) & $12.80(5.97)$ & $15.15(5.06)$ \\
Gov_effectivness (mean (sd)) & $41.26(13.59)$ & $39.88(13.12)$ \\
Political_terror (mean (sd)) & $-0.53(0.60)$ & $-0.66(0.36)$ \\
Corruption (mean (sd)) & $3.64(0.91)$ & $3.22(0.97)$ \\
Child_labor_law (mean (sd)) & $-0.66(0.47)$ & $-0.80(0.46)$ \\
Public_spending (mean (sd)) & $0.51(0.50)$ & $0.62(0.49)$ \\
\hline
\end{tabular}


Table 2. Definition of child poverty and its deprivations

\section{Child Deprivation}

$\mathbf{N}$

Proportion

Water: Children who only have access to surface water (e.g., rivers) for drinking or who

$1,941,734$

0.24

lived in households where the nearest source of water was more than 15 minutes away.

Children $<18$ years old.

Malnutrition: Children whose heights and weights for their age were more than -3 standard

deviations below the median of the international reference, that is, severe anthropometric

failure. Children $<5$ years old.

Shelter: Children in dwellings with more than five people per room and/or with no flooring material. Children $<18$ years old.

Sanitation: Children who had no access to a toilet of any kind in the vicinity of their dwelling, that is, no private or communal toilets or latrines. Children $<18$ years old.

Health: Children who has not been immunized against diseases or young children who had a recent illness involving diarrhea and had not received any medical advice or treatment. [polio, measles, DPT (against diphtheria, pertussis, and tetanus), tuberculosis (Bacillus Calmette-Guérin) recommended by the WHO (cf. 2013)]. Children $<5$ years old

Information: Children with no access to radio, television, telephone, or newspaper at home. Children 3-17 years old.

Education: Children who had never been to school and were not currently attending school, in other words, no professional education of any kind. Children 7-17 years old.

Absolut poverty: Children who suffers from two or more deprivations, as defined above. Children $<18$ years old. 


\section{Figures}

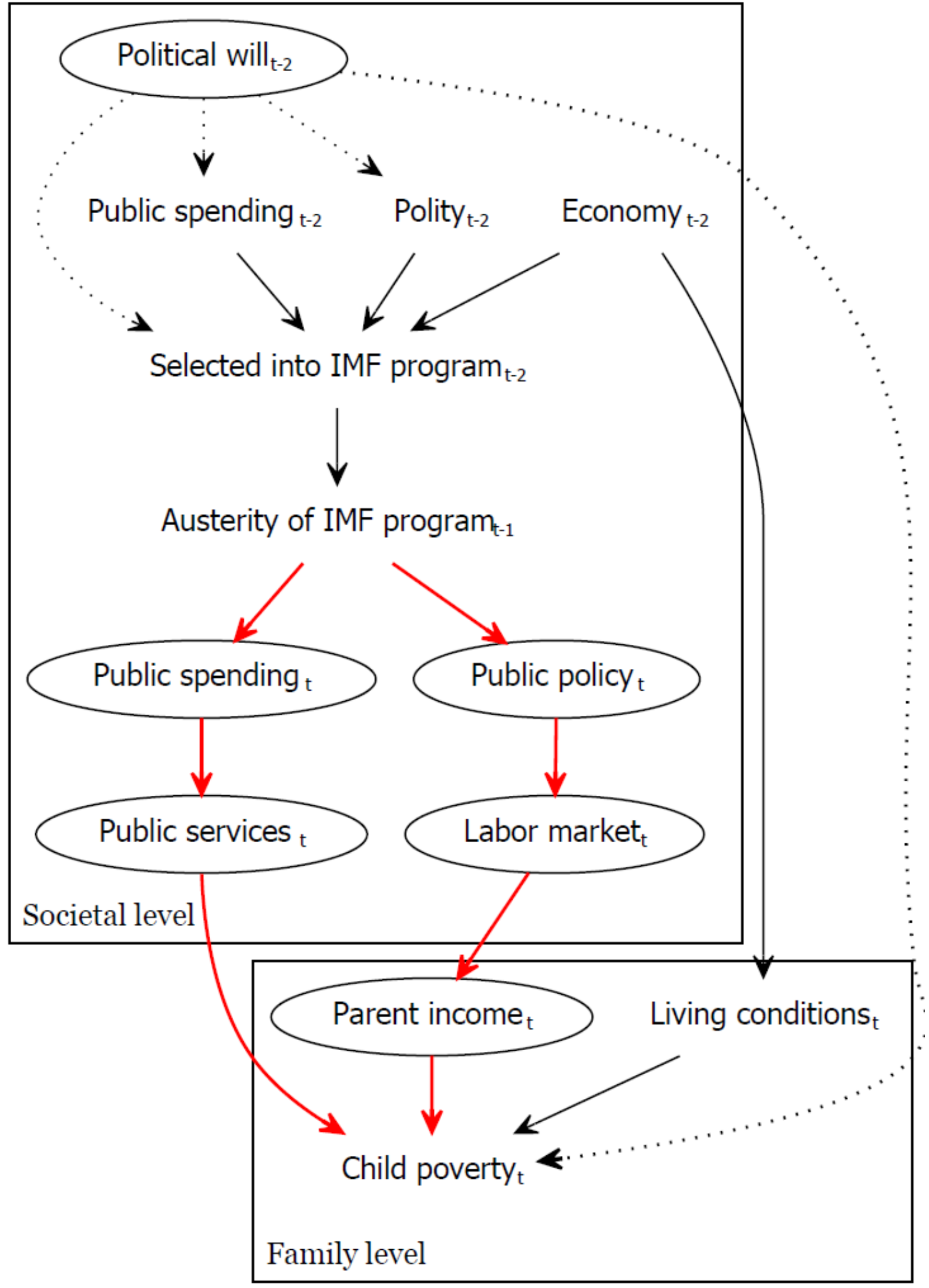


Figure 1. Causal assumptions pictured in a directed acyclic graph (DAG) 

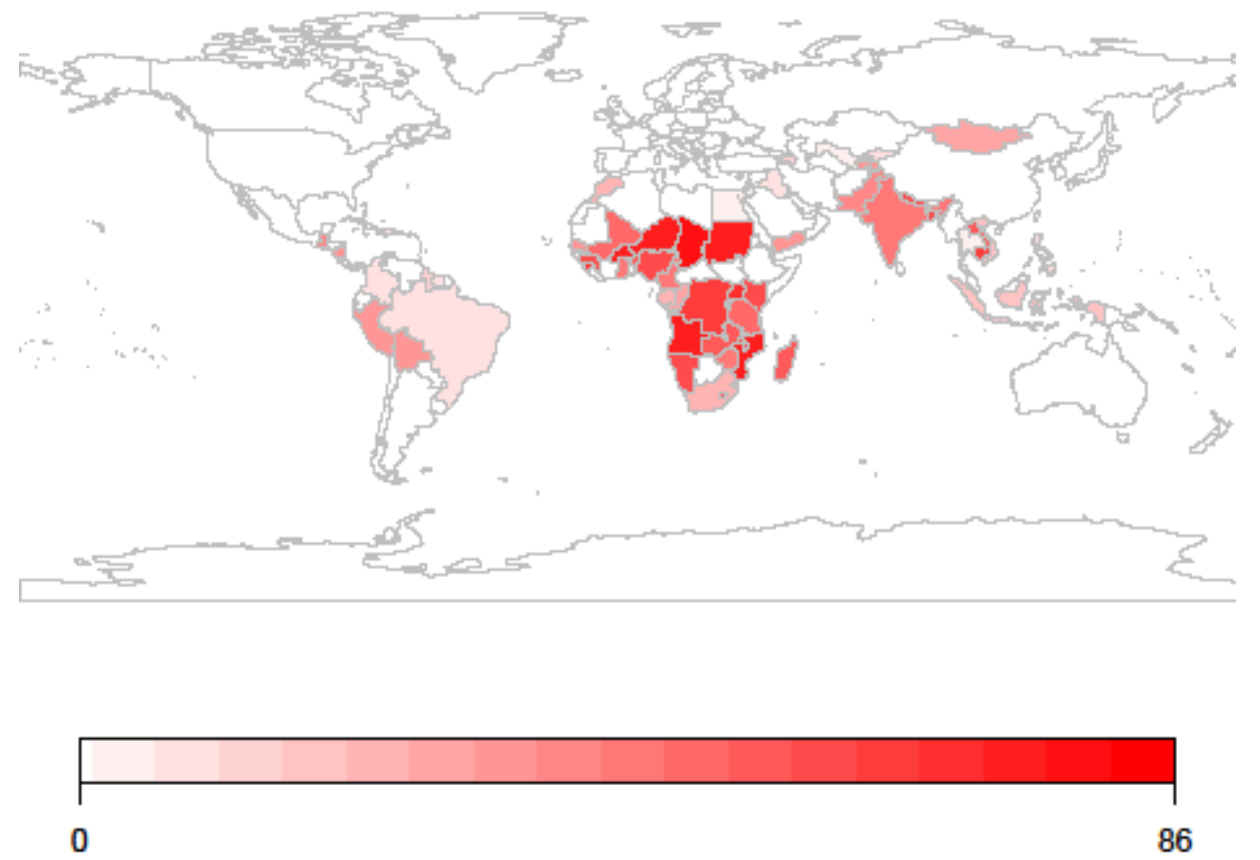

Figure 2. World distribution of child poverty

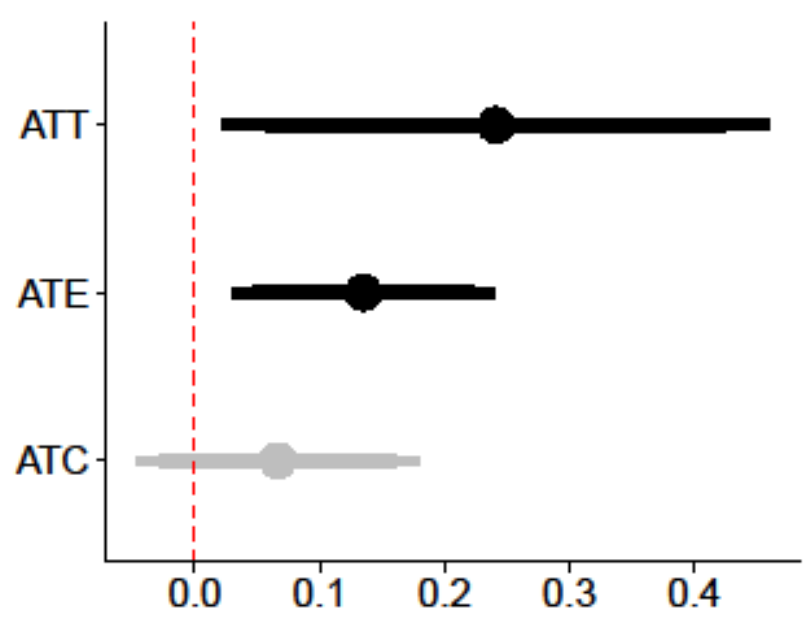

Probability of child poverty due to austerity

Figure 3. Quantities of interest 


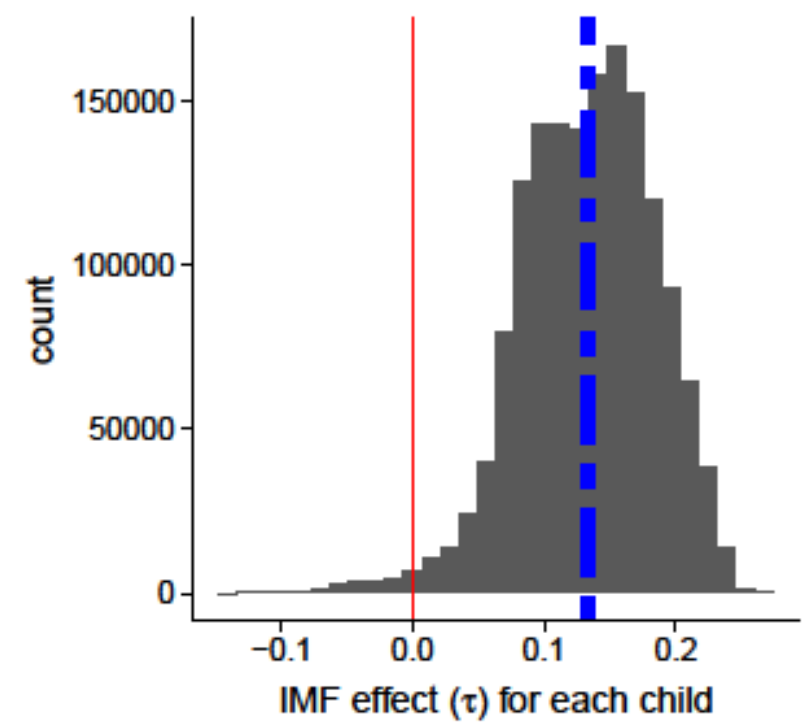

Figure 4. Histogram of individual-level treatment effect - IMF impact heterogeneity 


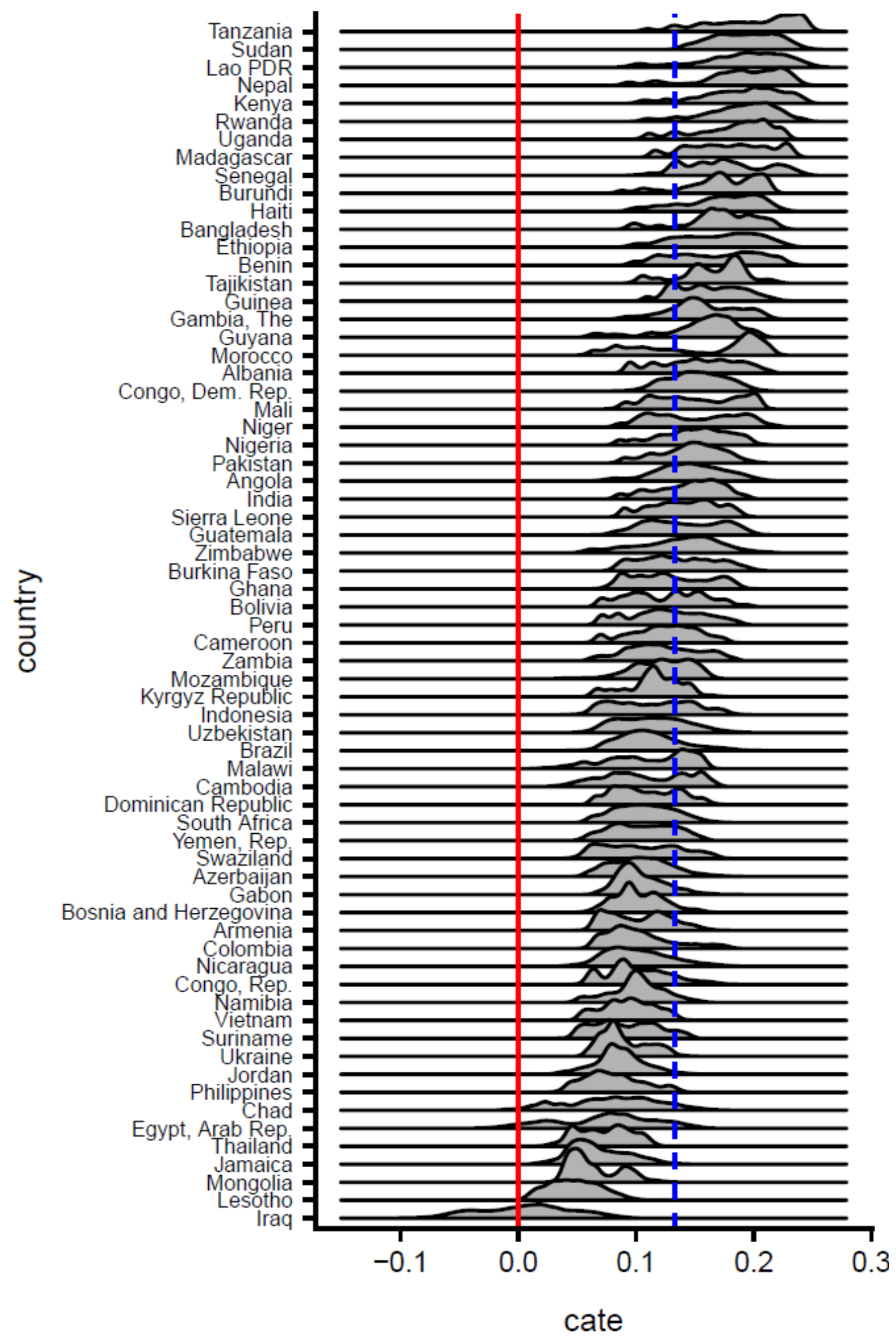

Figure 5. IMF impact heterogeneity by society 


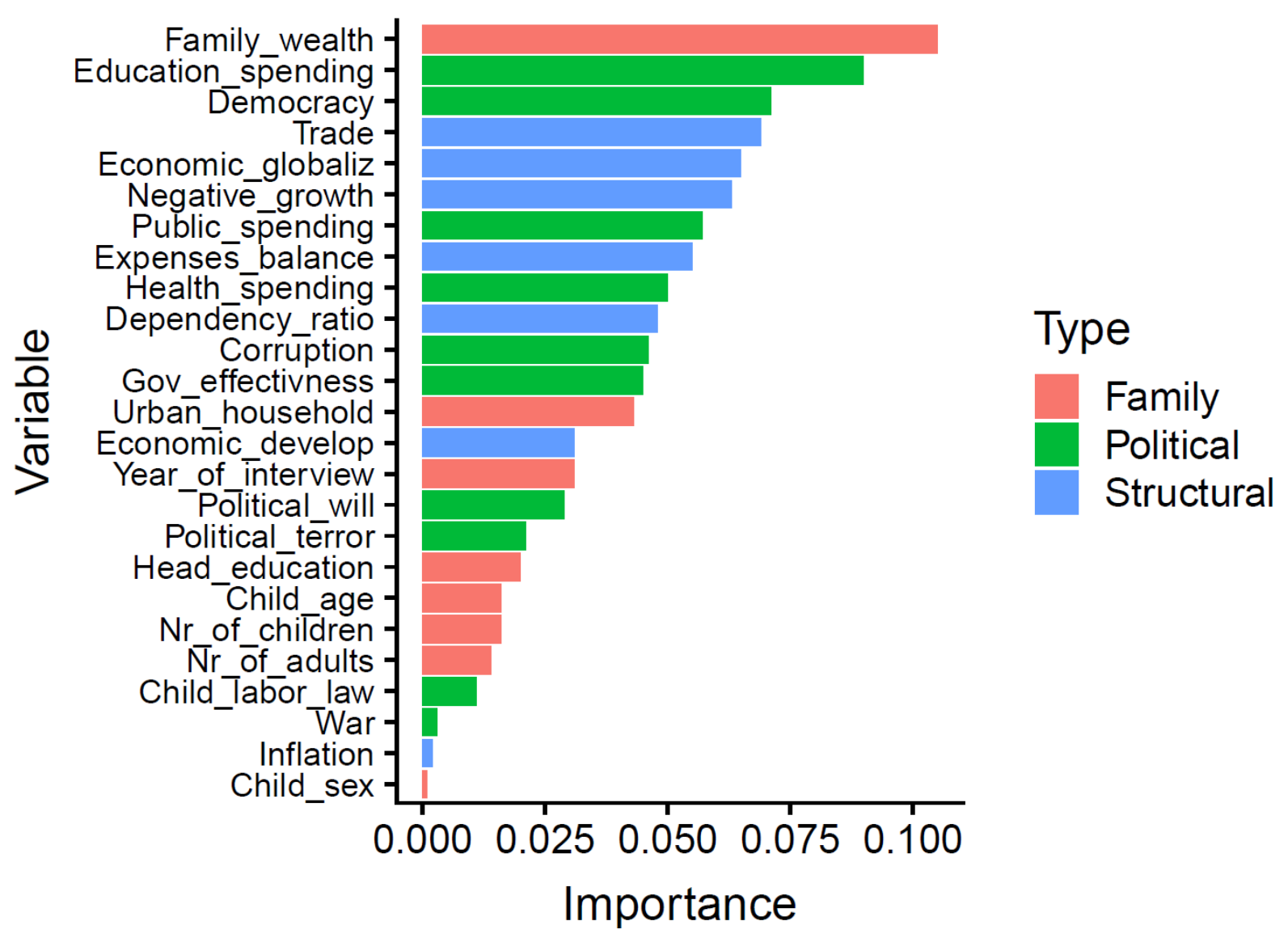

Figure 6. Variable importance moderating impact heterogeneity 


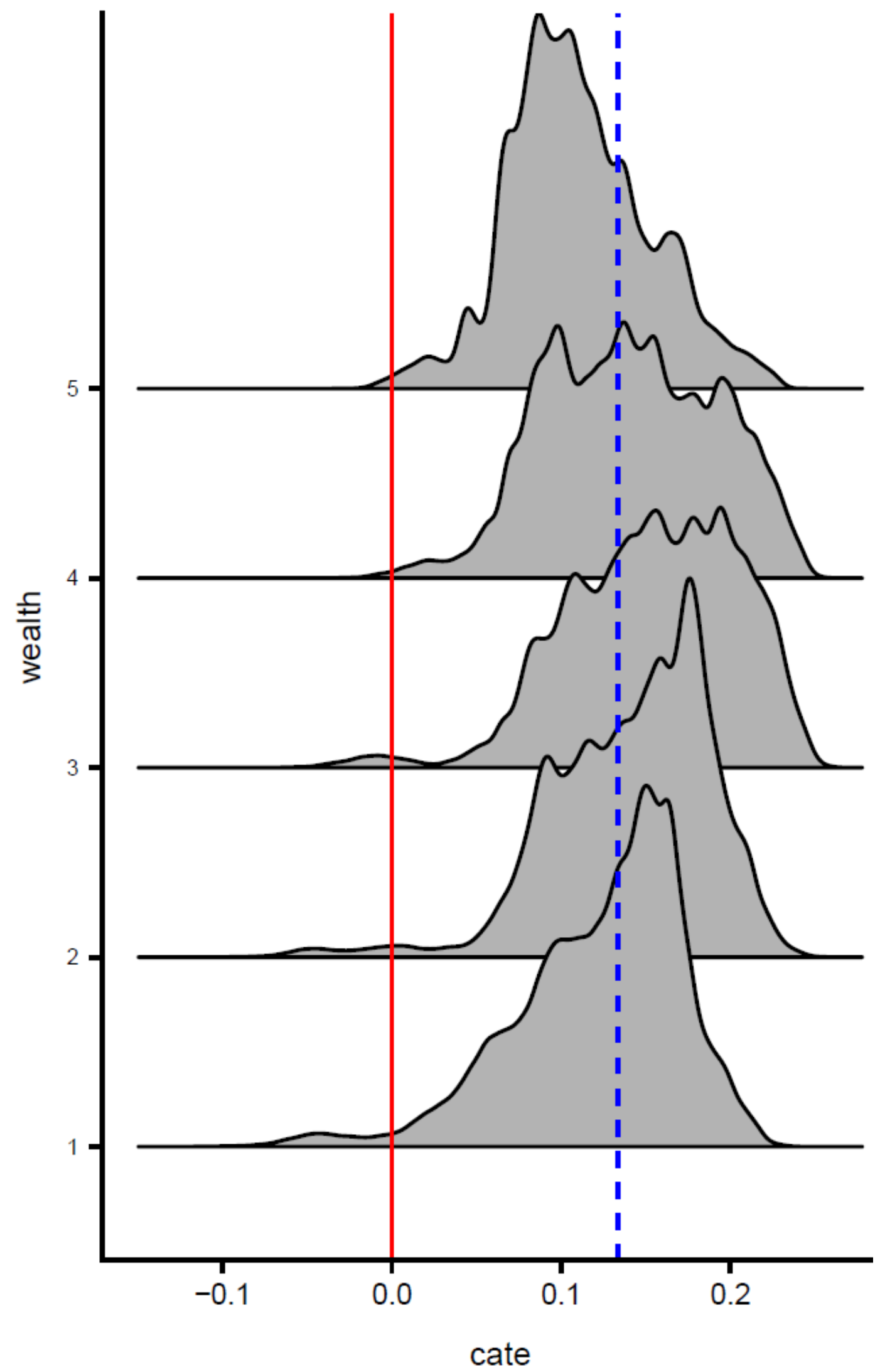

Figure 7. Family wealth moderating impact heterogeneity by quintile 


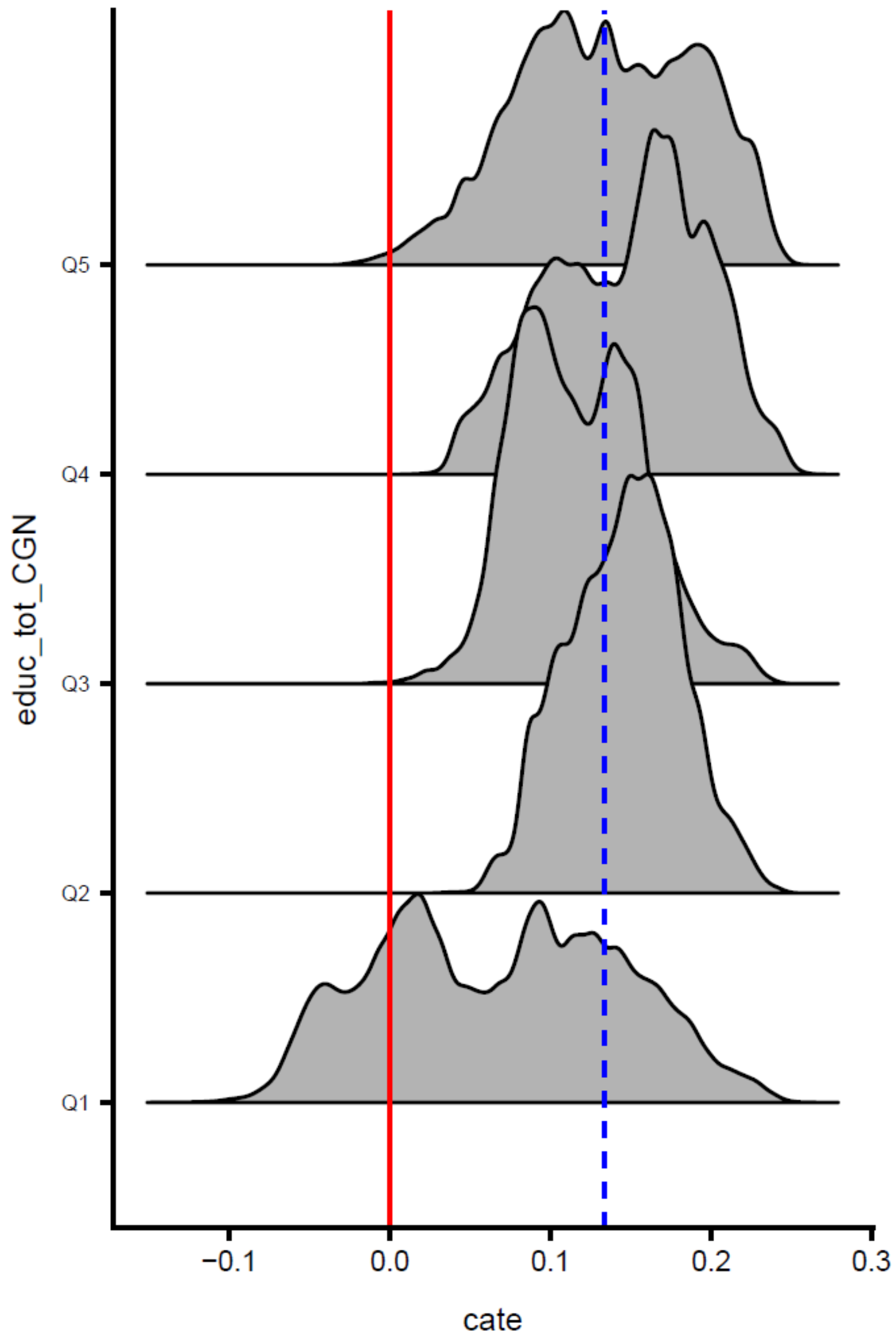

Figure 8. Education spending moderating impact heterogeneity by quintile 


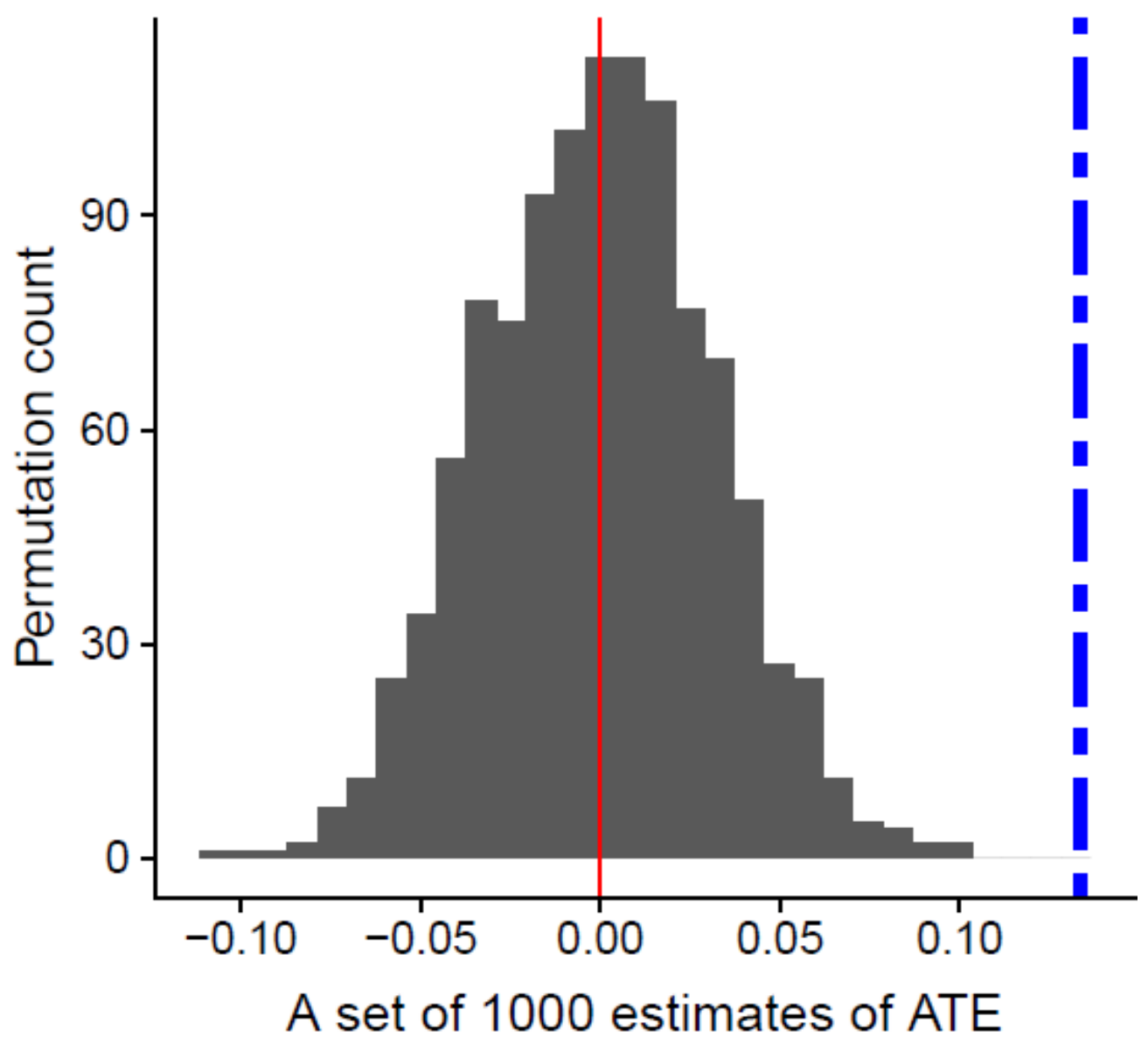

Figure 9: Permutation test results 


\section{Appendix}

\subsection{Appendix A: Measures}

\begin{tabular}{|c|c|c|}
\hline Variable & Definition & Source \\
\hline \multicolumn{3}{|l|}{ Country-level } \\
\hline \multicolumn{3}{|l|}{ variables } \\
\hline Health spending & $\begin{array}{l}\text { Measured as a share of GDP, and as a share of total } \\
\text { government expenditures. }\end{array}$ & $\begin{array}{l}\text { IMF, 2011, and World } \\
\text { Development Indicators }\end{array}$ \\
\hline IMF program & $\begin{array}{l}\text { Dummy variable produced by the IMF: 'the starting year of } \\
\text { an IMF-supported program [is defined] as the year in which } \\
\text { the program was approved, provided this occurred in the } \\
\text { first half of the year. If the approval date was in the second } \\
\text { half of the year, the starting year is the following year. The } \\
\text { end year is the year in which the program expired.' }\end{array}$ & IMF, 2011. \\
\hline GDP per capita & $\begin{array}{l}\text { Gross domestic product per capita (constant } 2000 \text { USD) - } \\
\text { logged (to correct for the skewed distribution). }\end{array}$ & WDI, Sep. 2012. \\
\hline $\begin{array}{l}\text { Government } \\
\text { balance }\end{array}$ & $\begin{array}{l}\text { General government balance (share of GDP). Calculated by } \\
\text { subtracting general government expenditure from general } \\
\text { government revenue. }\end{array}$ & $\begin{array}{l}\text { Authors' calculation using IMF- } \\
\text { WEO data. }\end{array}$ \\
\hline High inflation & $\begin{array}{l}\text { Dummy variable: }=1 \text { if year-to-year change in inflation } \\
\text { over } 20 \%, 0 \text { otherwise. }\end{array}$ & $\begin{array}{l}\text { Authors' calculation using IMF- } \\
\text { WEO data. }\end{array}$ \\
\hline Dependency ratio & $\begin{array}{l}\text { Combined shares of populations aged } 0-14 \text { and } 65 \text { and } \\
\text { above. }\end{array}$ & $\begin{array}{l}\text { Authors' calculations using WDI } \\
\text { data. }\end{array}$ \\
\hline Trade & $\begin{array}{l}\text { Trade is the sum of exports and imports of goods and } \\
\text { services measured as a share of gross domestic product. }\end{array}$ & WDI, Sep. 2012 \\
\hline Democracy & $\begin{array}{l}\text { Democracy, Range: } 0-10 \text { (Freedom House/Imputed Polity). } \\
\text { Average of Freedom House and Polity (transformed to a } \\
\text { scale 0-10). Hadenius \& Teorell (2005) show that this } \\
\text { average index performs better both in terms of validity and } \\
\text { reliability than its constituent parts. }\end{array}$ & $\begin{array}{l}\text { Quality of Governance Database, } \\
2011 .\end{array}$ \\
\hline Negative growth & $\begin{array}{l}\text { Dummy variable: }=1 \text { if negative growth in a given year, } 0 \\
\text { otherwise. }\end{array}$ & $\begin{array}{l}\text { Authors' calculation using IMF- } \\
\text { WEO data. }\end{array}$ \\
\hline ODA & Net ODA received (\% of GNI). & WDI, Sep. 2012 \\
\hline Low income country & $\begin{array}{l}\text { Dummy variable. Country is eligible for concessional } \\
\text { lending from the IMF }\end{array}$ & IMF, 2011 \\
\hline Sub-Saharan Africa & $\begin{array}{l}\text { Dummy variable. Refers to countries located south of the } \\
\text { Sahara Desert. }\end{array}$ & World Development Indicators \\
\hline Civil war & Magnitude score of episode(s) of civil warfare & Center for Systemic Peace \\
\hline $\begin{array}{l}\text { Education } \\
\text { expenditure (\% of } \\
\text { GDP) }\end{array}$ & Public education spending as a percentage of GDP & $\begin{array}{l}\text { Clements, Gupta \& Nozaki 2011, } \\
\text { What happens to social spending } \\
\text { in IMF-Supported programs? }\end{array}$ \\
\hline
\end{tabular}




\begin{tabular}{llll}
\hline $\begin{array}{l}\text { Education } \\
\text { expenditure (\% of } \\
\text { gov. spending) }\end{array}$ & Public education spending as a percentage of total & Clements, Gupta \& Nozaki 2011, \\
govent spending & & What happens to social spending \\
in IMF-Supported programs?
\end{tabular}

Economic globalization

Government effectiveness

Corruption

Political terror

Minimum age labor law

Government spending

\section{Family-level variables}

Nr children

Nr of Adults
The KOF Globalisation Index measures the economic, social and political dimensions of globalisation.

"Combines into a single measure of the quality of public service provision, the quality of the bureaucracy, the competence of civil servants, the independence of the civil service from political pressures, and the credibility of the government's commitment to policies. The index focus on the "inputs" required for the government to be able to produce and implement good policies and deliver public goods”. (Teorell et al. 2018)

"measures perceptions of corruption, defined as the exercise of public power for private gain. It measures aspects of corruption ranging from the frequency of "additional payments to get things done", to the effects of corruption on the business environment, to measuring "grand corruption" in the political arena or in the tendency of elite forms to engage in "state capture". (Teorell et al. 2018)

Measures political terror on a scale 1 to 5 , where 5 is the most severe form of terror. This level is defined as, "Terror has expanded to the whole population. The leaders of these societies place no limits on the means or thoroughness with which they pursue personal or ideological goals” (Teorell et al. 2018)

Dummy variable: = 1 a law in place regulating minimum required working age , 0 otherwise

Government expenditure (Percent of GDP)

Number of individuals under the age of 18

Number of individuals over the age of 18
Economic globalization, Dreher 2006, KOF Index of Globalization (Version: March 2016)

Interpolated, World Bank, Worldwide Governance Indicators

Interpolated, World Bank, Worldwide Governance Indicators.

Political terror scale (U.S. State Department), Gibney, Cornett \& Wood 2013, Political Terror Scale..

Minimum Age Convention, 1973 (No. 138), International Labour Organization (ILO), Information System on International Labour Standards

(NORMLEX) (Retrieved 2014: http://www.ilo.org/normlex IMF in Quality of Governance Database, 2011
Demographic and Health Survey; Multiple Indicator Cluster Survey

Demographic and Health Survey; Multiple Indicator Cluster Survey 


\begin{tabular}{|c|c|c|}
\hline Education & Ordinal variable (no education, primary, and secondary+). & Demographic and Health Survey; \\
\hline & Measures the head of household's level of education. & $\begin{array}{l}\text { Multiple Indicator } \quad \text { Cluster } \\
\text { Survey }\end{array}$ \\
\hline Wealth index & $\begin{array}{l}\text { Ordinal variable (Quintiles). The index is a composite } \\
\text { measure of the household's material standard. It is } \\
\text { calculated from selected assets such as ownership of } \\
\text { television, mobile phones, bicycles. }\end{array}$ & $\begin{array}{l}\text { Demographic and Health Survey; } \\
\text { Multiple Indicator Cluster } \\
\text { Survey. (Rutstein 2008) }\end{array}$ \\
\hline Urban rural & $\begin{array}{l}\text { Dummy variables. Captures the geographical location of } \\
\text { households. }\end{array}$ & $\begin{array}{l}\text { Demographic and Health Survey; } \\
\text { Multiple Indicator Cluster } \\
\text { Survey }\end{array}$ \\
\hline Child-level variables & & \\
\hline $\begin{array}{l}\text { Severe child health } \\
\text { deprivation }\end{array}$ & $\begin{array}{l}\text { Dummy variable. Children under the age of } 5 \text { who had not } \\
\text { been immunized against diseases or had a recent illness } \\
\text { involving diarrhea and had not received any medical advice } \\
\text { or treatment two weeks prior to the survey }\end{array}$ & $\begin{array}{l}\text { Demographic and Health Survey; } \\
\text { Multiple Indicator Cluster } \\
\text { Survey. (Gordon et al. 2003:8) }\end{array}$ \\
\hline Sex of the child & Dummy variable. & $\begin{array}{l}\text { Demographic and Health Survey; } \\
\text { Multiple Indicator Cluster } \\
\text { Survey }\end{array}$ \\
\hline Age & Age of the child in number of years. & $\begin{array}{l}\text { Demographic and Health Survey; } \\
\text { Multiple Indicator Cluster } \\
\text { Survey }\end{array}$ \\
\hline
\end{tabular}

\subsection{Appendix B: Heckman Selection model}

Governments' select into IMF programs. This produces selection bias where poorer countries might be more often cooperating with the IMF. If so, IMF treatment effect might erroneously be attributed to cause poverty. While observable variables affecting both selection into an IMF programme and child poverty are already included as controls in our model, we cannot directly control for unobservable factors such as 'political will', as outlined in our DAG.

Four approaches have been used in the IMF program evaluation literature to address this type of selection bias: matching methods; instrumental variable approaches; system GMM estimation; and Heckman selection models. For our purposes, Heckman's two-step method is the most suitable choice to address concerns of selection bias as it produces a proxy for unobserved factors that we can include into our set of controls. The Heckman model involves first modelling IMF participation, and second modelling the outcome of interest using the inverse Mills ratio from the first step. Accordingly, in the first step, we estimate a probit model to predict the likelihood of IMF participation:

$$
\begin{aligned}
& \Phi\left(Z_{k, t} \gamma\right)=\operatorname{Probit}\left(i m f . p r o g . c g n_{k, t}\right)=\gamma_{0}+\gamma_{1} \text { imf.prog.cgn } n_{k, t-1}+\gamma_{2} \text { gdp.growth } \text { }_{k, t-1}+ \\
& \gamma_{3} \text { cab.gdp } p_{k, t-1}+\gamma_{4} \text { demo.f }_{\text {f }} \text { pol }_{k, t-1}+\gamma_{5} \text { lngdppc }_{k, t-1}+\gamma_{6} \text { civilwar }_{k, t-1}+ \\
& \gamma_{7} \text { int.war }{ }_{k, t-1}+\gamma_{9} U \text { Nvote } G 7_{k, t-1}+\gamma_{10} \text { CountriesWithIMF } F_{k, t-1}
\end{aligned}
$$

As a point of reference, we rely on a version of the specification suggested by the Independent Evaluation Office of the IMF (IEO 2003): one that retain the best data coverage but which still gives analogous results. The outcome variable, imf.prog. $\operatorname{cgn}_{k, t}$, measures if country $k$ had an IMF program at year $t$. Our choice of which central mechanism affect selection into programs, builds on Moser and Strum’s suggestions (Moser and Sturm 2011): 
- Previous IMF participation (imf.prog.cgn, t-1): a country's past involvement with the IMF tend to positively determine future program participation. The nearer historically, the more likely participation is. We use whether the country had a program last year.

- GDP growth (gdp.growth): Countries with lower growth are more likely to become economically constrained, and ask for IMF credit.

- Current account balance (cab.gdp as share of GDP): One of the key objective of the IMF is to support countries to overcome balance of payment issues deriving from trade. The higher the imbalance, the more likely the country is to ask for IMF help.

- Democracy (demo.fhpol): Autocratic regimes can with less political cost invite the IMF, compared to more democratic countries.

- Log GDP per capita (lngdppc): low income countries tend to seek concessional IMF assistance, whereas middle income countries with short term economic disturbances (e.g. currency crisis) tend to ask for non-concessional loans (e.g. Brazil, Argentina).

- Civil war (civilwar): Even if countries with a high degree of domestic civil conflict might need more economic help, the IMF might avoid involvement during violent periods. Also, the political cost to call for IMF assistance might be high.

- International war (int.war): Countries involved in armed conflicts between sovereign nations deters the IMF.

- UN votes with G7 (UN vote G7): this variable captures how often countries vote in line with G7. This shows political proximity with the key nations driving the IMF.

- Countries on IMF programs (CountriesWithIMF): In any given year, the more countries that have IMF funding, the less likely the IMF is to issue new programs as its funds are limited.

The total number of countries on IMF programmes and UN voting patterns with G7 act as our exclusion restrictions: these variable explain significantly the country's participation decision in IMF programs but are not correlated with the dependent variable of the outcome equation, in our case child poverty. Voting pattern has stronger relevance as it is significantly correlated in all alternative selection specifications.

We choose not to include government balance (lagged one year) as it reduced many observations due to missing data. We would lose 6 countries reducing our data size by $10 \%$. We calculate the inverse Mills ratio and include it in the outcome equation to control for the remaining unobserved variation (Heckman 1979). The equation below defines the inverse Mills ratio, $\lambda$, which isolates unobserved factors determining IMF participation:

$$
\lambda_{k, t}= \begin{cases}\phi\left(Z_{k, t} \hat{\gamma}\right) / \Phi\left(Z_{k, t} \hat{\gamma}\right), & \text { if } T_{k, t}=1 \\ -\phi\left(Z_{k, t} \hat{\gamma}\right) /\left(1-\Phi\left(Z_{k, t} \hat{\gamma}\right)\right), & \text { otherwise. }\end{cases}
$$

The Mills ratio is calculated for each observation: country $k$ at time point $t$, and depending on their treatment status $T_{j}$ (present or absent IMF program). The function $\phi$ denotes the standard normal density function, and $\Phi$ the standard normal cumulative distribution function; $Z_{k, t}$ represents the covariates and $\hat{\gamma}$ are the vector of estimated parameter from the first equation. The inverse Mills ratio, $\lambda$, is then used as a covariate, in the outcome equation (in our case, the multilevel models with child poverty as outcomes) controlling for self-selection. In a linear model, its coefficient is interpreted as follows: if significantly negative, then unobserved variables that make IMF participation more likely are associated with lower government health 
expenditure; if significantly positive, then unobserved variables that make IMF participation more likely are associated with higher government health expenditure; if non-significant, then there is no association.

Alternative selection specifications

\begin{tabular}{|c|c|c|c|}
\hline & \multicolumn{3}{|c|}{$\begin{array}{l}\text { Dependent variable } \\
\text { IMF program (t) }\end{array}$} \\
\hline & M1 & M2 & M3 \\
\hline IMF program (t-1) & $\begin{array}{l}1.910^{* * *} \\
(0.064)\end{array}$ & $\begin{array}{l}1.959^{* * *} \\
(0.094)\end{array}$ & \\
\hline GDP growth (t-1) & $\begin{array}{c}-0.018^{* * *} \\
(0.006)\end{array}$ & $\begin{array}{c}-0.042^{* * *} \\
(0.010)\end{array}$ & $\begin{array}{c}-0.026^{* * *} \\
(0.009)\end{array}$ \\
\hline Current account balance (t-1) & $\begin{array}{c}-0.007^{*} \\
(0.004)\end{array}$ & $\begin{array}{c}-0.008 \\
(0.005)\end{array}$ & $\begin{array}{l}-0.008^{*} \\
(0.005)\end{array}$ \\
\hline Democracy (t-1) & $\begin{array}{l}0.027^{* *} \\
(0.013)\end{array}$ & $\begin{array}{l}0.033^{*} \\
(0.019)\end{array}$ & $\begin{array}{l}0.046^{* * *} \\
(0.016)\end{array}$ \\
\hline Log GDP per capita (t-1) & $\begin{array}{c}-0.256^{* * *} \\
(0.034)\end{array}$ & $\begin{array}{c}-0.253^{* * *} \\
(0.053)\end{array}$ & $\begin{array}{c}-0.336^{* * *} \\
(0.054)\end{array}$ \\
\hline Log aid per capita (t-1) & & & $\begin{array}{c}0.004 \\
(0.004)\end{array}$ \\
\hline Civil war (t-1) & $\begin{array}{c}-0.026 \\
(0.035)\end{array}$ & $\begin{array}{c}0.042 \\
(0.069)\end{array}$ & $\begin{array}{c}0.030 \\
(0.054)\end{array}$ \\
\hline International war (t-1) & $\begin{array}{c}0.042 \\
(0.072)\end{array}$ & $\begin{array}{c}-0.213 \\
(0.156)\end{array}$ & \\
\hline Dependency ratio (t-1) & & & $\begin{array}{c}-0.002 \\
(0.004)\end{array}$ \\
\hline Countries on IMF programs & $\begin{array}{l}0.011^{* * *} \\
(0.004)\end{array}$ & $\begin{array}{c}0.006 \\
(0.005)\end{array}$ & $\begin{array}{c}0.001 \\
(0.005)\end{array}$ \\
\hline UN voting pattern with G7 & $\begin{array}{l}0.886^{* *} \\
(0.419)\end{array}$ & $\begin{array}{l}1.041^{*} \\
(0.546)\end{array}$ & $\begin{array}{c}3.303^{* * *} \\
(0.686)\end{array}$ \\
\hline Constant & $\begin{array}{l}-0.570^{*} \\
(0.309)\end{array}$ & $\begin{array}{l}-0.418 \\
(0.478)\end{array}$ & $\begin{array}{l}-0.130 \\
(0.741)\end{array}$ \\
\hline Observations & 2,482 & 1,264 & 1,066 \\
\hline Log Likelihood & $-1,000.302$ & -471.559 & -631.869 \\
\hline Akaike Inf. Crit. & $2,020.605$ & 963.118 & $1,283.739$ \\
\hline
\end{tabular}

